\title{
LA INTERVENCIÓN FISCAL DEL ESTADO EN EL FORTALECIMIENTO DE LA PRODUCCIÓN INDUSTRIAL EN LAS REGIONES: EL CASO ARGENTINO RECIENTE $(2003-2015)^{*}$
}

Recibido: 05 de octubre de 2017 - Aprobado: 19 de diciembre de 2017

DOI: 10.22395/seec.v21n47a3

\author{
Alcides Bazza** \\ Víctor Ramiro Fernández ${ }^{* * *}$
}

\section{RESUMEN}

En el presente trabajo se analiza el impacto fiscal del Estado (nacional y provincial) en el fortalecimiento de la producción industrial en las regiones, tomando el caso argentino durante el periodo 2003-2015. Para ello se consideraron, bajo una metodología cuantitativa de análisis, la evolución de la inversión pública, los subsidios económicos y los gastos tributarios, y su incidencia sobre la capacidad productiva industrial de cada región. A través de este análisis se reconocieron ciertas limitaciones en la intervención fiscal para promover políticas estructurales que otorguen sostenibilidad al crecimiento económico alcanzado durante 2003-2010. En consecuencia, y pese a los importantes avances durante el periodo inicial, la desaceleración económica de 2011 afectó directamente los procesos de ampliación de la capacidad productiva industrial regional y la reducción de brechas de desarrollo interregional.

\section{PALABRAS CLAVE}

Intervención fiscal; Estado nacional; Provincias; Capacidades productivas industriales; Regiones; Argentina

CLASIFICACIÓN JEL

E62; $\mathrm{E} 63 ; \mathrm{H} 2 ; \mathrm{H} 54 ; \mathrm{H} 76 ; \mathrm{O} 18 ; \mathrm{O} 23$

\section{CONTENIDO}

Introducción; 1. Breves consideraciones teóricas para el análisis del caso argentino reciente; 2. La intervención fiscal del Estado (nacional y provincial) en el fortalecimiento de la producción industrial en las regiones; 3. Conclusiones; Bibliografía.

\footnotetext{
Este trabajo de reflexión es resultado de proyectos enmarcados en el Grupo de Investigación Desarrollo, Estado y Políticas Públicas, radicado en el Instituto de Humanidades y Ciencias Sociales del Litoral (Conicet-UNL).

* Abogado, Universidad Católica de Santa Fe, Ciudad de Santa Fe, Argentina. Especialista en Derecho de la Empresa, Universidad Nacional del Litoral, Santa Fe, Argentina. Doctorando en Ciencias Políticas, Universidad Nacional de Rosario (UNR), Santa Fe, Argentina. Investigador, Instituto de Humanidades y Ciencias Sociales del Litoral (IHuCSo Litoral), Santa Fe, Argentina. Profesor en la Facultad de Ciencias Jurídicas y Sociales, Universidad Nacional del Litoral (UNL), Santa Fe, Argentina. Teléfono: +54 (0342) 4575140. Dirección: Francia 2357, piso 3 - Dpto. C (CP: 3000). Correo electrónico: alcidesbazza@gmail.com.

"* Abogado, Universidad Nacional del Litoral (UNL), Ciudad de Santa Fe, Argentina. Master en Ciencias Sociales (Orientación Sociología), Facultad Latinoamericana de Ciencias Sociales (Flacso), Buenos Aires, Argentina. Doctor en Ciencias Políticas de la Universidad Autónoma de Madrid, España. Director del Instituto de Humanidades y Ciencias Sociales del Litoral (IHuCSo Litoral), Santa Fe, Argentina. Profesor de la Facultad de Humanidades y Ciencias (FHUC), Universidad Nacional del Litoral (UNL), Santa Fe, Argentina. Dirección: Pedro Díaz Colodrero 2462 (CP: 3000). Teléfono: +54 (0342) 4575140. Correo electrónico: rfernand@fcjs.unl.edu.ar.
} 


\title{
THE STATE'S FISCAL INTERVENTION IN THE STRENGTHENING OF INDUSTRIAL PRODUCTION IN THE REGIONS: THERECENT CASE OF ARGENTINA (2003-2015)
}

\begin{abstract}
In this paper, the fiscal impact of the State (national and provincial) in the strengthening of industrial production in the regions is analyzed, taking the Argentine case during the period 2003-2015. For this purpose, the evolution of public investment, financial assistances and tax expenditures, and their impact on the industrial productive capacity of each region were considered under a quantitative analysis methodology. Through this analysis, certain limitations were recognized in the fiscal intervention to promote structural policies that give sustainability to the economic growth that was achieved between 2003 and 2010.Consequently, and despite the important advances during the initial period, the economic slowdown of 2011 directly affected the processes of expansion of the regional industrial productive capacity and the reduction of interregional development gaps.
\end{abstract}

\section{KEYWORDS}

Fiscal intervention; National State; provinces; Industrial productive capacities; Regions; Argentina

\section{JEL CLASSIFICATION}

E62; E63; H2; H54; H76; O18; O23

\section{INTERVENÇÃO FISCAL DO ESTADO NO FORTALECIMENTO DA PRODUÇÃO INDUSTRIAL NAS REGIÕES: 0 RECENTE CASO ARGENTINO (2003-2015)}

\section{RESUMO}

Neste artigo analisamos o impacto fiscal do Estado (nacional e provincial) no fortalecimento da produção industrial nas regiões, tomando o caso argentino no período 2003-2015. Sendo assim, considerou-se a evolução do investimento público, subsídios econômicos e gastos tributários, e seu impacto na capacidade produtiva industrial de cada região, sob uma metodologia de análise quantitativa. Através dessa análise, certas limitações na intervenção fiscal foram reconhecidas para promover políticas estruturais que deem sustentabilidade ao crescimento econômico alcançado durante 2003-2010. Consequentemente, e apesar dos importantes avanços durante o período inicial, a desaceleração econômica de 2011 afetou diretamente os processos de expansão da capacidade produtiva industrial regional e a redução das brechas de desenvolvimento inter-regional.

\section{PALAVRAS-CHAVE}

Intervenção fiscal; estado nacional; províncias; capacidades produtivas industriais; regiões; Argentina.

\section{CLASSIFICAÇÃO JEL}

E62, E63, H2, H54, H76, O18, O23.

\section{CONTEÚDO}

Introdução; 1. Breves considerações teóricas para a análise do recente caso argentino; 2. Intervenção fiscal do Estado (nacional e provincial) no fortalecimento da produção industrial nas regiões; 3. Conclusões; Bibliografia. 
La intervención fiscal del Estado en el fortalecimiento de la producción industrial en las regiones: el caso argentino ...

\section{INTRODUCCIÓN}

Las históricas desigualdades productivas regionales que caracterizan a América Latina en general, y a Argentina en particular, se encuentran directamente vinculadas a la particular forma de inserción internacional de este grupo de países en la economía mundial. Frente a esta problemática — ampliamente abordada en autores como Rofman y Romero (1997), y Fernández et al. (2008), entre otros-, las formas en que el Estado se vinculó para alterar este proceso variaron a lo largo del tiempo.

Durante el periodo de posguerra (1945-1970), bajo el pleno apogeo del modelo sustitutivo de importaciones, el Estado argentino — en este caso, el nacional — implementó diversos planes con el fin de integrar socioeconómicamente las diversas regiones al desarrollo económico nacional (véanse Cao y Rubins, 1996; y Rofman, 1982). Pese a sus limitaciones, se alcanzaron avances exponenciales en el fortalecimiento de la capacidad productiva de la industria, así como en la reducción de brechas de desarrollo.

Con las reformas neoliberales implementadas desde mediados de la década de 1970 y consolidadas en la de 1990, se promovió la apertura económica como aspecto estratégico para garantizar la competitividad interregional, bajo la libre regulación del mercado (Rofman, 1997; Manzanal, 1999). Así, se llevó adelante una desvinculación del Estado nacional en su rol para fortalecer el entramado productivo-industrial (Fernández et al., 2005) y una fuerte intervención de este para viabilizar el ajuste estructural, con activa participación de los niveles subnacionales (Fernández, 1999) . Estas políticas fueron causa de una reprimarización de la estructura productiva, lo que agravó las desigualdades regionales-industriales.

Frente a este escenario, que encontraría su punto cúlmine con la crisis de 2001, emergió una reacción, denominada por algunos neodesarrollista, que, como destacaron Grugel y Riggirozzi (2012), Sader (2009) y Ferrer (2007), puso nuevamente el foco de atención en la reintervención del Estado como actor central para el desarrollo, otorgando especial centralidad a la necesidad de llevar adelante un fortalecimiento industrial nacional y revertir así las desigualdades productivas regionales. Sin embargo, transcurrida una década y media de su arribo al poder estatal y luego del actual giro a la derecha que se vislumbra en la política nacional, el presente trabajo se propuso indagar cuáles fueron los alcances de esta reacción.

En este sentido, sin desconocer las distintas funciones de la intervención estatal —nacional y provincial — que inciden directamente en el fortalecimiento de la capacidad productiva de la industria en las regiones, este trabajo se centra en el análisis fiscal. La relevancia de la fiscalidad no solo deviene, como lo indica Tilly (1990), de ser esta última uno de los elementos históricos de conformación del 
Estado que, en los términos de Mann (1993; 2013), hacen a su poder territorial centralizado. También, por su rol central en el estímulo de la demanda efectiva para promover el crecimiento económico (véanse Kalecki, 2002; Amico, 2013a), y, en adición, su relevancia para viabilizar transformaciones estructurales de base industrial.

Para ello, se consideraron la evolución de la inversión pública, los subsidios económicos (nacionales y provinciales) y los gastos tributarios (nacionales), y su incidencia cuantitativa sobre la capacidad productiva de la industria de cada región. A través de este análisis se reconocieron ciertas limitaciones en la intervención fiscal para promover políticas estructurales que otorguen sostenibilidad al exponencial crecimiento económico alcanzado durante el periodo 2003-2010, así como a las transformaciones de las capacidades productivas regionales y la reducción de brechas de desarrollo interregional.

El trabajo se organiza en dos secciones. En la primera se esbozan brevemente los aspectos teórico-conceptuales para introducir el análisis del caso argentino reciente. La segunda, por su parte, avanza sobre el objetivo propuesto en este y se divide en cuatro apartados: en los primeros dos se consideran la evolución de la inversión pública y de los subsidios económicos nacionales y provinciales-regionales; en el tercero se indagan los gastos tributarios nacionales; y en el cuarto se observa la evolución de la capacidad productiva de la industria en el escenario regional. Las conclusiones procuran articular los resultados observados en función del marco conceptual y los objetivos propuestos.

\section{BREVES CONSIDERACIONES TEÓRICAS PARA EL ANÁLISIS DEL CASO ARGENTINO RECIENTE}

La inserción periférica en la división internacional del trabajo que caracteriza a los países latinoamericanos en general, y al caso argentino en particular, plantea restricciones sobre su desarrollo económico y regional. Esta condición, ampliamente reconocida por el pensamiento estructuralista latinoamericano en autores como Prebisch (1986) y Pinto (1972), entre otros, constituye el punto de partida para comprender los límites estructurales que se presentan sobre estos países. Su rol como proveedores de recursos primarios refuerza, por un lado, su dependencia a las importaciones de bienes de capital para alterar, en los términos de Hirschman (1961), sus estructuras productivas heterogéneas y desequilibradas; y por otro lado, acentúa la lógica circular de la acumulación subyacente a su interior, que profundiza las diferencias regionales en favor de las regiones - y enclaves dentro de estas regiones- que concentran los recursos exportados en detrimento de las más pobres (véanse Rofman y Romero, 1997, y Gorenstein, 2015). 
La intervención fiscal del Estado en el fortalecimiento de la producción industrial en las regiones: el caso argentino ...

En este proceso que, lejos a atenuarse, tiende a ser profundizado cuando actúan los mecanismos de poder inherentes a la estructura del mercado, el Estado se convierte en un actor clave para incentivar el fortalecimiento de la producción industrial como forma de revertir la circularidad de la acumulación y el fortalecimiento dirigido de los escenarios productivos industriales menos favorecidos. Si bien la forma como lo hace y las instancias estatales que intervienen resultan variables en el contexto de las transformaciones experimentadas por el capitalismo desde la posguerra, la instancia nacional preserva una presencia estratégica y ordenadora incuestionable (Fernández, 2010). Su relevancia histórica, dada por lo que Mann (1993 y 2013) entiende como el poder centralizado que ejerce sobre un territorio determinado, no ha sido anulada, sino reposicionada ante los cambios escalares y funcionales propagados por la globalización.

Si bien las modificaciones significativas en las formas de producción que comenzaron a tener lugar debido a los avances en las tecnologías de la comunicación —que, como identificó Castells (1989), permitieron a las empresas multinacionales operar simultáneamente a escala global y a tiempo real — marcaron redefiniciones sustantivas y fuertes desplazamientos de las competencias hacia arriba y hacia abajo (véanse Brenner, 2004 y Jessop, 2006), lejos estuvieron de conllevar la desaparición de los Estados nacionales. Este hecho no fue tampoco ajeno a los contextos periféricos: cumplió un papel central tanto en los procesos de desmantelamiento de las formas de protección desarrolladas durante la sustitución de importaciones (Fernández, 2001), como en el impulso de los exitosos procesos de industrialización generados en el este de Asia (Amsdem, 1989; Wade, 1999; Fernández y García Puente, 2013).

La transformación espacial organizacional que impone el proceso de globalización no solo ha mostrado esa perviviente, pero redefinida, significación de las instancias nacionales, sino también la paralela relevancia creciente de las escalas subnacionales. En función de su proximidad y mejor conocimiento de las actividades económicas regionales, así como de las demandas de flexibilidad que imponen los procesos de acumulación, las instancias subnacionales del estado han sido forzadas a cumplir un rol fundamental en la reorganización productiva e institucional en el escenario regional (Fernández y García Puente, 2012).

En función de estas cuestiones, el trabajo destaca la necesidad de la coordinación interestatal, en su intervención para el fortalecimiento de la producción industrial. Como lo ha señalado extensamente Fernández, la coordinación apunta a evitar, por un lado, una intervención vertical del Estado nacional que se desentienda de los intereses subnacionales. Y, por otro lado, una revalorización de los niveles 
subnacionales que obstaculice la articulación nacional y facilite una fragmentación debilitadora. Esta última, agudizada con el avance de la globalización, se presenta como consecuencia de las ventajas que recaen en pequeños enclaves regionales que, como islas de prosperidad —Veltz (1996)—, interactúan directamente con actores trasnacionales en completa desintegración con el Estado nacional y los demás espacios regionales.

A estos fines, y sin desconocer las múltiples dimensiones y aspectos de la intervención estatal (nacional y subnacional) que inciden directamente en el fortalecimiento de la capacidad productiva de la industria regional, este trabajo tomó el análisis fiscal. Como uno de sus elementos históricamente constitutivos (Tilly, 1990) y Mann (1993)—, la relevancia de la intervención fiscal se refleja en dos factores:

- Su capacidad para estimular la demanda efectiva y promover el crecimiento económico. Una política fiscal expansiva aumenta el gasto agregado y permite a las empresas vender más productos, con lo cual aumentan los ingresos y el empleo. En esta línea de análisis, un interesante grupo de autores como Kalecki (2002), Garegnani (1977), Cesaratto et al. (2003), Amico (2013a) argumentó que la producción total se determina por la demanda efectiva, que se define como los gastos agregados realizados a los precios normales de producción. Entre estos gastos agregados, la política fiscal ocupa un rol central en el corto y el largo plazos, fundamentalmente a través de los gastos corrientes; es decir, aquellos que se vinculan al funcionamiento del Estado y que hacen a sus actividades gubernamentales para el cumplimiento de las funciones.

- Es una dimensión clave del Estado para financiar y orientar procesos de industrialización, que promuevan cambios estructurales. Esta función adquiere particular relevancia en el contexto de países periféricos con estructuras productivas preponderantemente primarizadas, que presentan fuerte dependencia de las importaciones de bienes de capital. Así, una industrialización que sustituya importaciones, o bien que se oriente a ampliar las exportaciones, es clave para dar un salto al desarrollo económico, como lo destacan Amsdem (1989), Wade (1999) y Fernández y García-Puente (2013) en referencia al rol del Estado en las exitosas experiencias del este de Asia.

En relación con este segundo aspecto de la intervención fiscal, un elemento clave a considerar se relaciona con el gasto en capital. Este comprende aquellas erogaciones destinadas al conjunto de bienes y equipos durables de producción, maquinarias y bienes preexistentes que amplían la capacidad productiva de la in- 
dustrial en el ámbito nacional y regional, en relación con infraestructura económica y social. A diferencia de los gastos corrientes, el gasto en capital — que se refleja en la inversión real directa (considerada inversión pública en las cuentas nacionales), las transferencias de capital (realizadas a unidades de gobierno inferiores para financiar gastos de capital) y la inversión financiera - representa un tipo de intervención estatal específica asociada con su participación directa en la producción y la acumulación.

En complemento al gasto en capital, otros elementos de la acción del Estado son relevantes para analizar la intervención del Estado en el fortalecimiento de capacidades productivas, como el gasto en servicios económicos -incluidos los subsidios - y el gasto tributario (incentivos fiscales). El primero de ellos comprende las acciones de apoyo a la producción de bienes y servicios significativos para el desarrollo económico e Incluye energía, combustibles, minería, comunicaciones, transporte, ecología y medio ambiente, agricultura, industria, comercio y turismo. Por su parte, y de acuerdo con la Dirección Nacional de Información y Análisis Fiscal, el gasto tributario es el monto de ingresos que el fisco deja de percibir al otorgar un tratamiento impositivo que se aparta del establecido con carácter general en la legislación tributaria, con el objetivo de beneficiar a determinadas actividades, zonas, contribuyentes o consumos. Este es significativo para orientar la inversión en el ámbito provincial-regional.

Figura 1. Intervención estatal desde su fiscalidad nacional y provincial

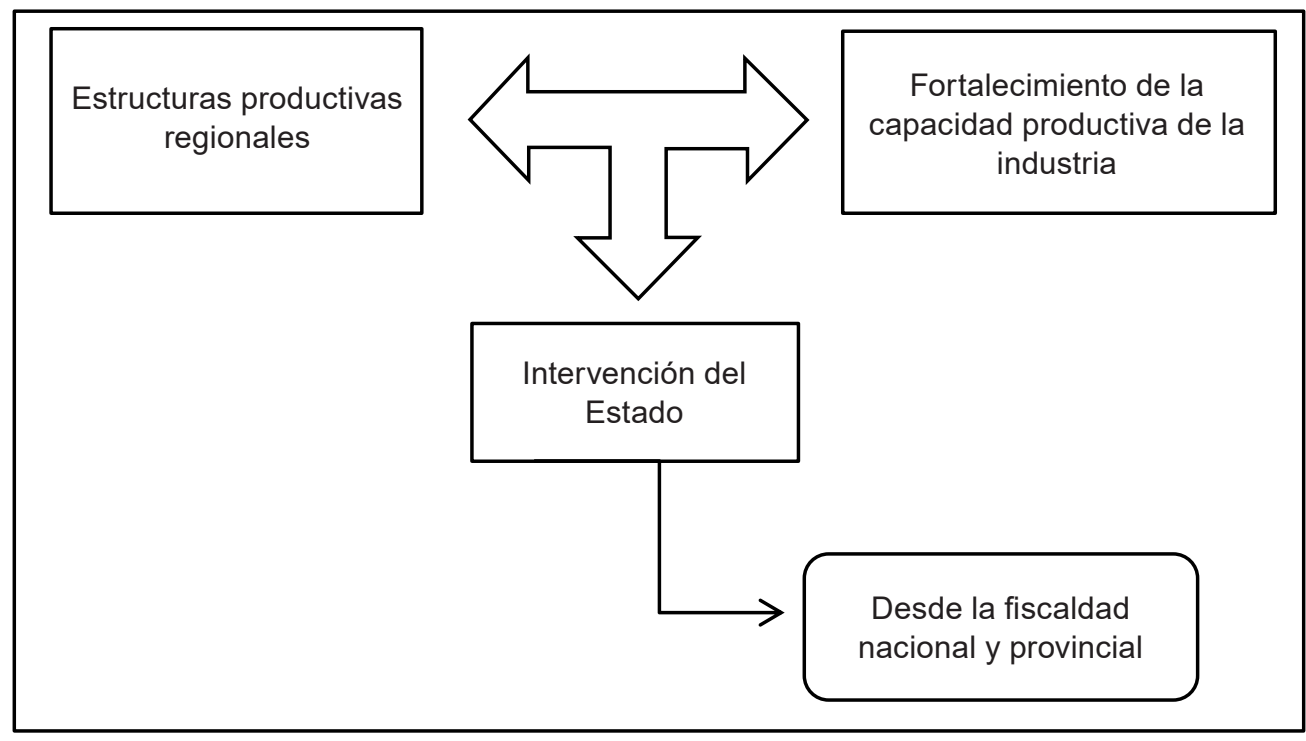

Fuente: elaboración propia. 


\section{INTERVENCIÓN FISCAL DEL ESTADO (NACIONAL Y PROVINCIAL) EN EL FORTALECIMIENTO DE LA PRODUCCIÓN INDUSTRIAL EN LAS REGIONES}

Bajo el marco de análisis brevemente esbozado, esta segunda sección se centra en el análisis específico del caso argentino. Luego de las profundas consecuencias ocasionadas por la crisis del 2001, Argentina experimenta un notable giro de su política macroeconómica desde 2003, y ello se manifestó, particularmente, en la política fiscal. La intervención fiscal ha tenido un contraste marcado respecto a la década anterior de reformas neoliberales y ello se tradujo, como lo sostuvieron Amico (2013a, 2013b) y Fiorito (2015), en el estímulo de todos los componentes de la demanda agregada nacional. Así, por ejemplo, el gasto primario del sector público argentino no financiero (SPANF) pasó del 31 \% al 45 \% del PIB entre los años 1993 y 2010, y ello se acompañó de un crecimiento exponencial de los ingresos fiscales totales (gráfico 1).

Gráfico 1. Ingresos y gastos del SPANF, 1993-2010 (en porcentaje del PIB)

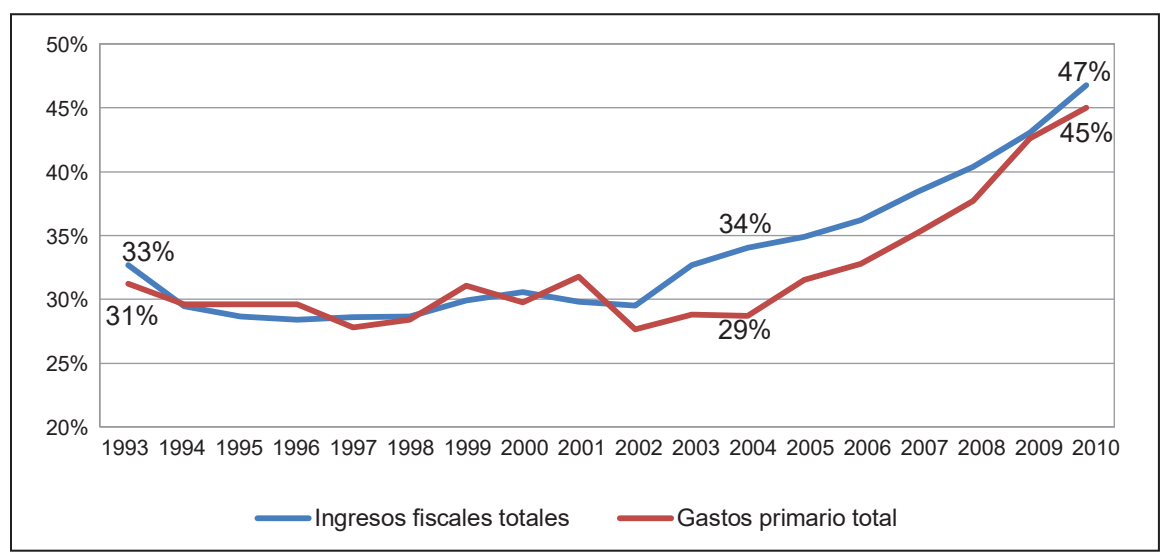

Fuente: elaboración propia con datos de la Oficina Nacional de Presupuesto (ONP).

El crecimiento del gasto primario fue destinado, principalmente, a los gastos corrientes. Entre estos se destacaron las remuneraciones, los gastos en bienes y servicios, y las prestaciones de la seguridad social. Así, durante los últimos años de la década de 1990 y principios de la siguiente, la variación porcentual del gasto en compra de bienes y servicios rondó valores inferiores al 13\%, y tuvo una importante recuperación desde 2003 en adelante (véase el gráfico 2). Por su parte, luego de la reducción de las remuneraciones en 2001 y 2002 — a 1 \%, y sus leves variaciones en los años previos (apenas 7 \% para el año 1999 y $2 \%$ para los 2000)—, las mismas contaron con un significativo crecimiento desde 2003. Si bien la variación porcentual 
La intervención fiscal del Estado en el fortalecimiento de la producción industrial en las regiones: el caso argentino ...

Gráfico 2. Gasto del SPANF en remuneraciones y bienes, 1994-2012 (variación porcentual nominal anual)

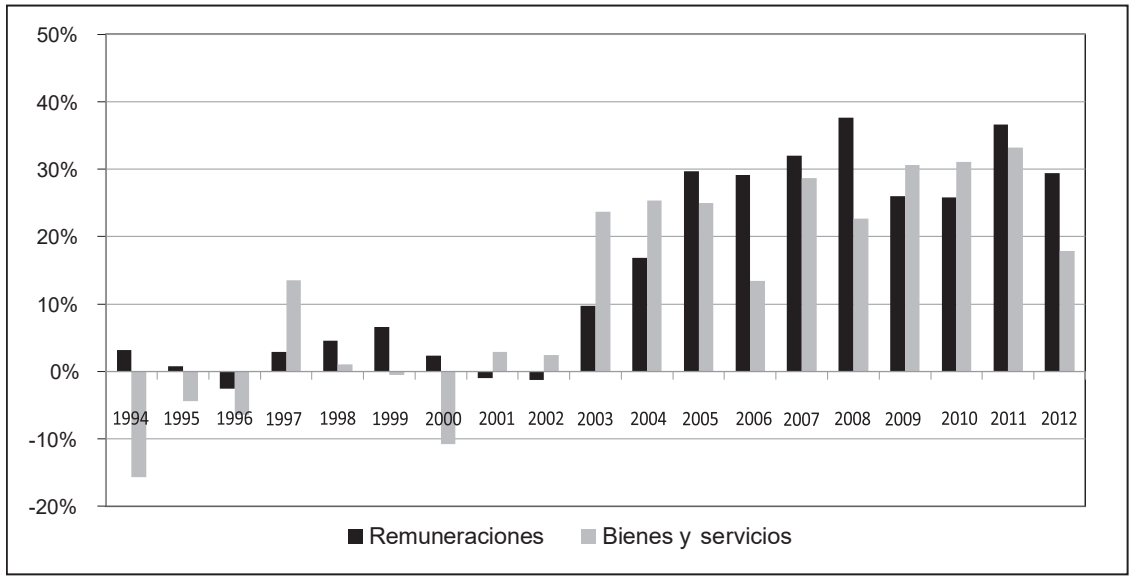

Fuente: elaboración propia con datos de la ONP.

anual de estos gastos se considera en términos nominales, la variación no deja de ser significativa.

Este claro contraste entre ambos periodos se ratifica con más fuerza cuando se observan las prestaciones a la seguridad social. Estas se incrementaron de forma notoria cuando se puso en práctica el llamado Plan de inclusión previsional, durante el primer semestre de 2007 (gráfico 3).

Gráfico 3. Prestaciones a la seguridad social del SPANF, 1994-2012 (variación porcentual nominal anual)

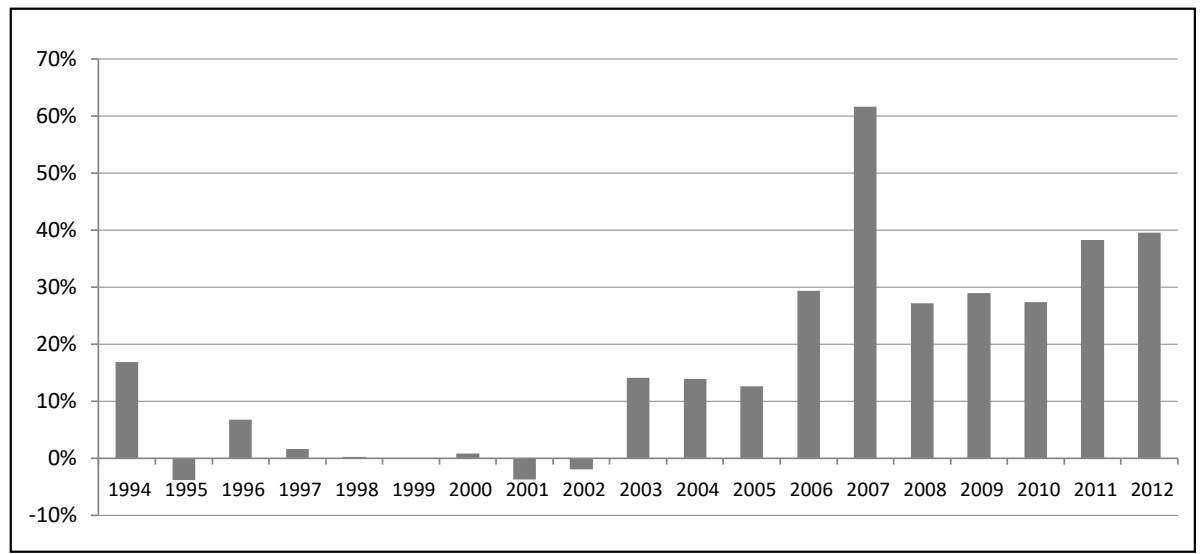

Fuente: elaboración propia con datos de la ONP. 
Sin dudas, estos tres componentes básicos del gasto público —remuneraciones, bienes y servicios, y prestaciones de la seguridad social — fueron factores centrales para estimular la demanda efectiva e inducir el crecimiento económico. Esto último dada la incidencia de estos gastos en el aumento de la masa salarial y el nivel de ingresos, que aumentaron el consumo público y privado (Amico, 2013a). Esos elementos de la demanda agregada explicaron, en gran parte, los elevados niveles de crecimiento promedio durante el periodo 2003-2008, que han superado los máximos alcanzados en la etapa de pleno auge del periodo sustitutivo (gráfico 4).

\section{Gráfico 4. Argentina: crecimiento del PIB, 1995-2012 (variación porcentual anual y promedio)}

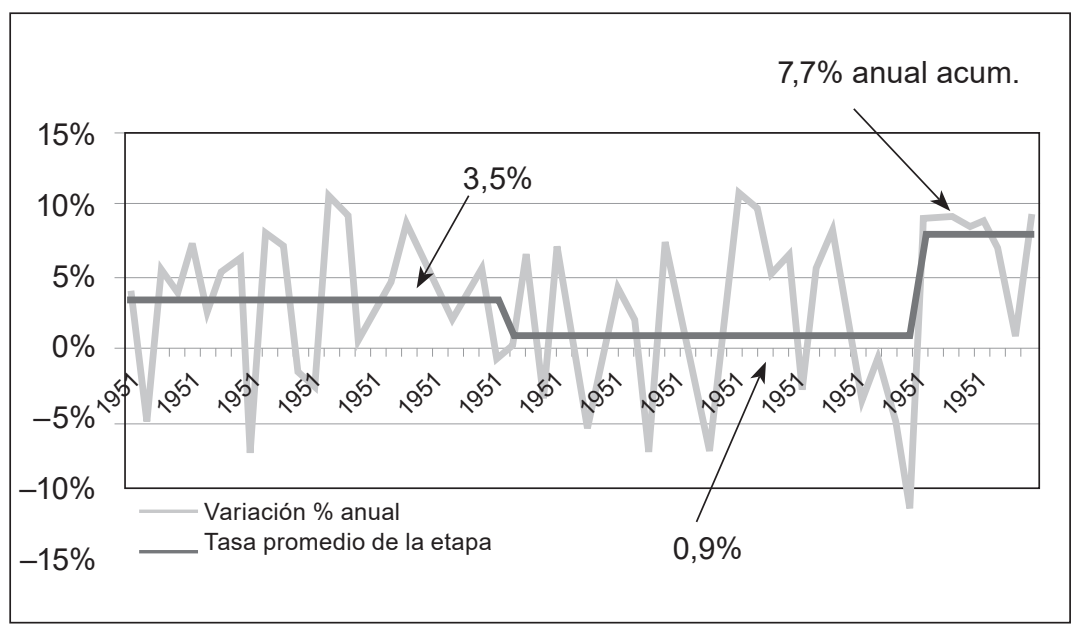

Fuente: Ferreres (2005), Cepal e Indec.

Este performance obtenido en el plano macroeconómico, en un marco favorable del contexto internacional que permitió ampliar la recaudación de los derechos de exportación e incrementó los ingresos fiscales (Amico, 2013a), abría un interesante campo de maniobra para comenzar a desplegar políticas de tipo estructural, que se orientaron a un mayor desarrollo nacional sobre la base de la producción industrial, enfrentando de esta manera problemáticas históricas. En este sentido, el presente trabajo se propuso indagar sobre los alcances de la intervención fiscal durante el periodo 2003-2015, para incidir en el fortalecimiento de la mencionada capacidad productiva de la industria regional, y alterar brechas de desarrollo.

Para lograr lo anterior se consideraron la inversión pública y los subsidios económicos en el ámbito nacional y provincial. A manera de complemento, se analizaron también los gastos tributarios nacionales. Estos tres aspectos forman parte de lo que en este trabajo se denominó intervención fiscal del Estado, haciéndose especial referencia a la incidencia cuantitativa de los mismos en la capaci- 
La intervención fiscal del Estado en el fortalecimiento de la producción industrial en las regiones: el caso argentino ...

dad productiva de la industria en las regiones. En relación con estas capacidades, el trabajo tomó los indicadores económicos del desarrollo regional (Iderp económico) elaborados por la Subsecretaría de Coordinación Provincial, dependencia de la Secretaría de Hacienda del Ministerio de Hacienda y Finanzas Públicas de la Nación.

\subsection{Inversión pública}

Un primer elemento sobre el cual se indagó fue la inversión pública del Estado (nacional y provincial), y se consideró también a la empresa pública. Se abordó exclusivamente la inversión real directa (IRD) del Spanf, que es propiamente considerada inversión pública en las cuentas nacionales e integra la inversión total del país.

Si bien fue notoria la diferencia respecto a los bajísimos niveles de IRD durante la etapa neoliberal de la década de 1990 — 1,5 \% del PIB_- en promedio, la inversión durante el periodo neodesarrollista $(2003-2012)^{1}$ — 2,58 \% del PIB — distó mucho de los promedios existentes en las décadas en las que tuvo vigencia el modelo sustitutivo de importaciones: ascendía a 6,70 \% del PIB en la década de 1990; alcanzó 8,30 \% en la de 1970; y llegó a 5,50 \% en la de 1980 (gráfico 5) —.

\section{Gráfico 5. Inversión real directa del Spanf, 1961-2012 (porcentaje promedio del PIB)*}

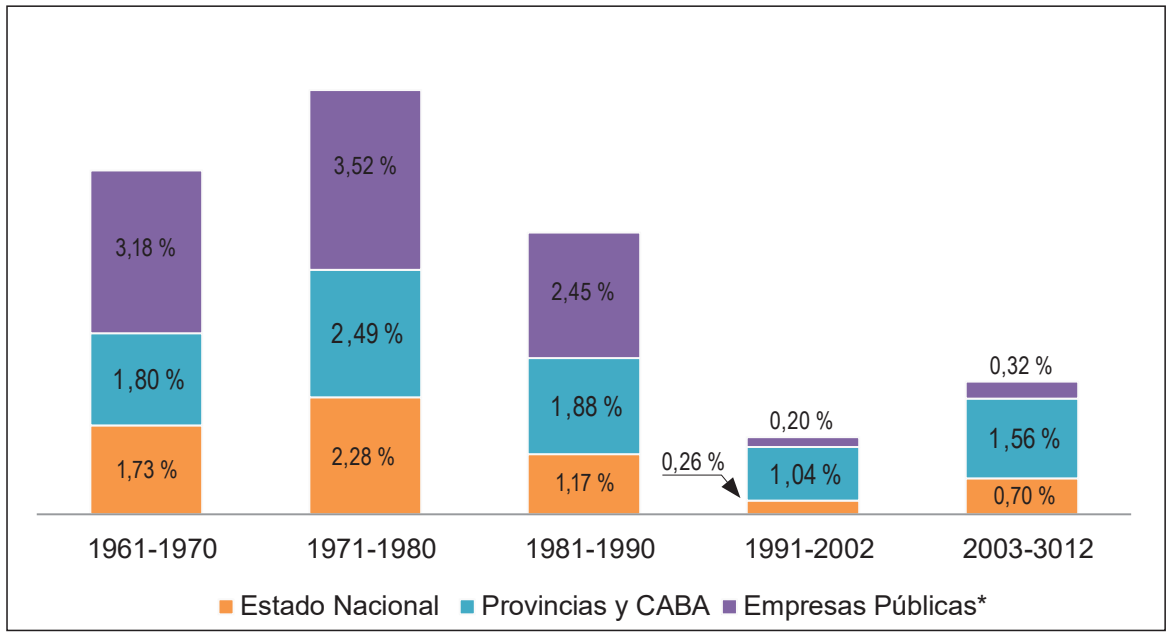

Nota: en la IRD en las empresas públicas solo se consideró a las nacionales. A su vez, se incluye en la misma la inversión realizada por parte de los fondos fiduciarios y otras entidades públicas, que comienzan a discriminarse en la cuenta AIF desde 2001 en adelante.

Fuente: elaboración propia con información de la ONP.

Se consideró este periodo hasta el año 2012 porque se tomó el PIB a precios corrientes de 1993, que es el seguido por la cuenta de Ahorro-Inversión-Financiamiento (AIF) desde 1961 a 2004. Véase al respecto Oficina Nacional de Presupuesto - ONP (2005). 
Sobre ese marco general, un aspecto a destacar fue el terreno perdido y no recuperado de la empresa pública luego de las reformas neoliberales. Así, se pudo observar que mientras en la década de 1970 la IRD de las empresas públicas alcanzaba el 3,52 \% del PIB — superando a las realizadas por el Estado nacional y provincial- esta inversión no fue preponderante durante la etapa neodesarrollista $-0,32 \%$ del PIB-.

Por otra parte, en lo que refiere específicamente a infraestructura económica, la inversión pública Argentina fue una de las más bajas entre los países de la región. Luego del auge exponencial del gasto en capital durante el periodo 2003-2007, este performance fue notablemente inferior durante el periodo 2008-2015 respecto de los países vecinos, como se observó en los casos de Bolivia y Paraguay (gráfico 6). A su vez, los países que presentaron niveles similares de inversión pública a la Argentina, como Brasil y Chile, contaron con el mayor promedio de inversión privada.

En este contexto, el gasto provincial destinado a IRD tuvo importantes diferencias cuando se lo comparó por regiones. Se observó, entonces, que la región Centro solo invirtió la mitad de su producto bruto geográfico (PBG), mientras que las regiones con menor PBG (NEA y NOA) presentaron el mayor porcentaje de inversión: 19 \% (gráfico 7). A su vez, las regiones Patagonia y Cuyo ocuparon el segundo y tercer lugar en la generación del PBG — 9 \% y 7 \% del total, respectivamente-. y aun con ello tuvieron los niveles de IRD más bajos frente a las demás regiones.

Gráfico 6. Inversión en infraestructura económica, promedio 2008-2015 (porcentaje del PIB)

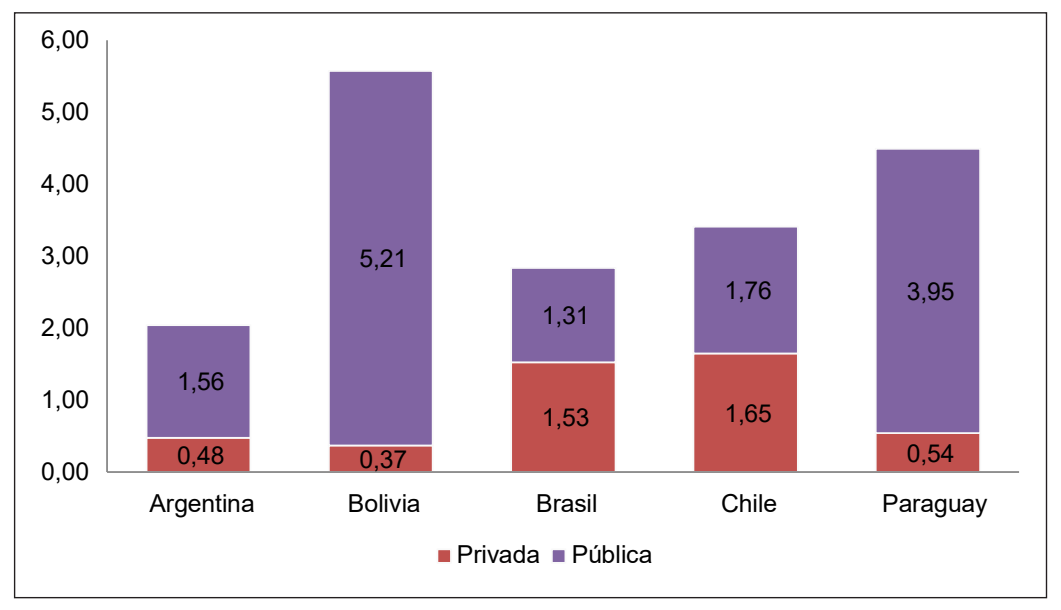

Fuente: elaboración propia con datos de Infralatam-Cepal²

\footnotetext{
Se reportan los recursos destinados a inversión en infraestructura económica (agua y saneamiento, defensas contra inundaciones, energía, riego, telecomunicaciones y transporte). Se considera la
} 
La intervención fiscal del Estado en el fortalecimiento de la producción industrial en las regiones: el caso argentino ...

\section{Gráfico 7. $\mathrm{PBG}^{3}$ e IRD por regiones, 2003-2014 (promedio porcentual)}

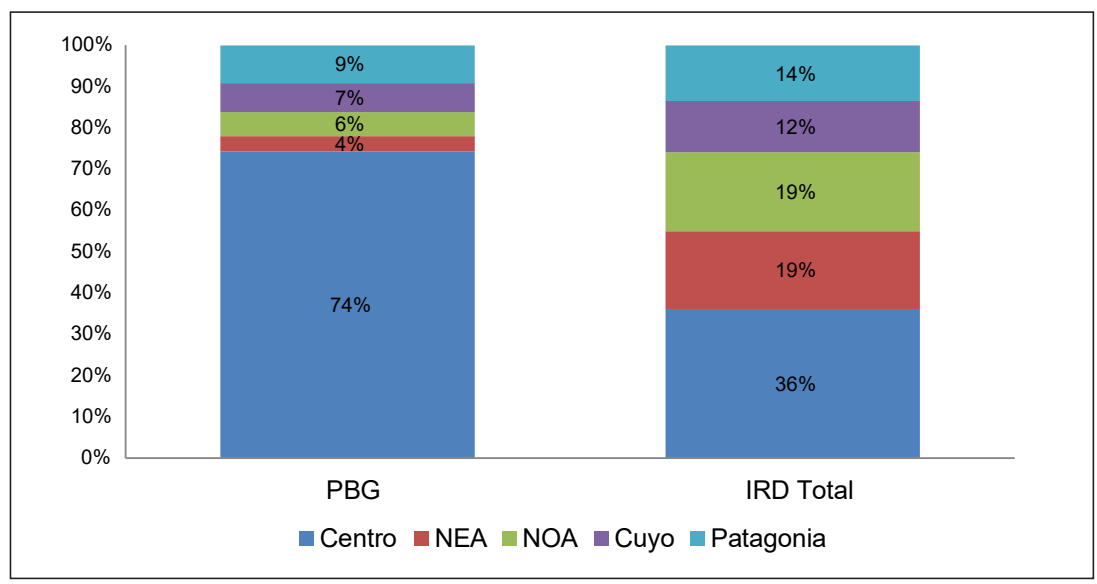

Fuente: elaboración propia con datos de la Asociación Argentina de Presupuesto (ASAP), Dirección Nacional de Coordinación Fiscal con las Provincias (DNCFP) y Subsecretaría de Coordinación Provincial.

Una explicación significativa para entender estas diferencias se encontró en la fuerte dependencia de la IRD provincial de las transferencias de capital nacional (gráfico 8). Estas comenzaron a adquirir mayor participación desde 2005 y se ratificaron en $2009^{5}$, al representar más de la mitad del total de inversión provincial.

Sin embargo, tuvieron una importante disminución desde 2011 con un impacto en la inversión provincial y contaron con criterios dispares en su distribución, de difícil justificación. En este sentido, el carácter dependiente de la inversión provincial a las transferencias nacionales, así como el criterio dispar en la distribución por provincias de estas últimas, obedecieron a problemas concretos de coordinación fiscal. Estos reconocen como una de sus causas principales a los históricos problemas del régimen coparticipable ${ }^{6}$

inversión realizada por el sector público, incluyendo tanto a las empresas públicas no financieras como al gobierno general, que puede comprender tres o más niveles de gobierno (central; estatal, provincial o regional; y local). Para el caso argentino, las inversiones subnacionales sólo se registran respecto a aquéllas realizadas con fondos transferidos desde el gobierno nacional. Para una mayor información sobre la metodología utilizada, consultar: http://infralatam.info/

3 Se tomó el producto bruto geográfico del año 2005 (en millones de pesos), el último actualizado.

4 En millones de pesos.

5 En ese año se creó el Fondo Federal Solidario, en el que se resolvió coparticipar en un 30 \% el total de recursos recaudados sobre los derechos de exportación a la soya y sus derivados, bajo los mismos porcentajes que estipula la Ley de coparticipación n. ${ }^{\circ} 23.548$. A su vez, se estableció la obligación a las provincias de coparticipar un $30 \%$ de lo recibido a sus municipios.

6 No se puede desarrollar con mayor extensión esta cuestión aquí. No obstante, es pertinente hacer referencia a la histórica centralización de recursos tributarios en el Estado nacional, que se sostiene con 
Gráfico 8. IRD provincial y transferencias de capital nacional, 2005-2015 (porcentaje del PIB)

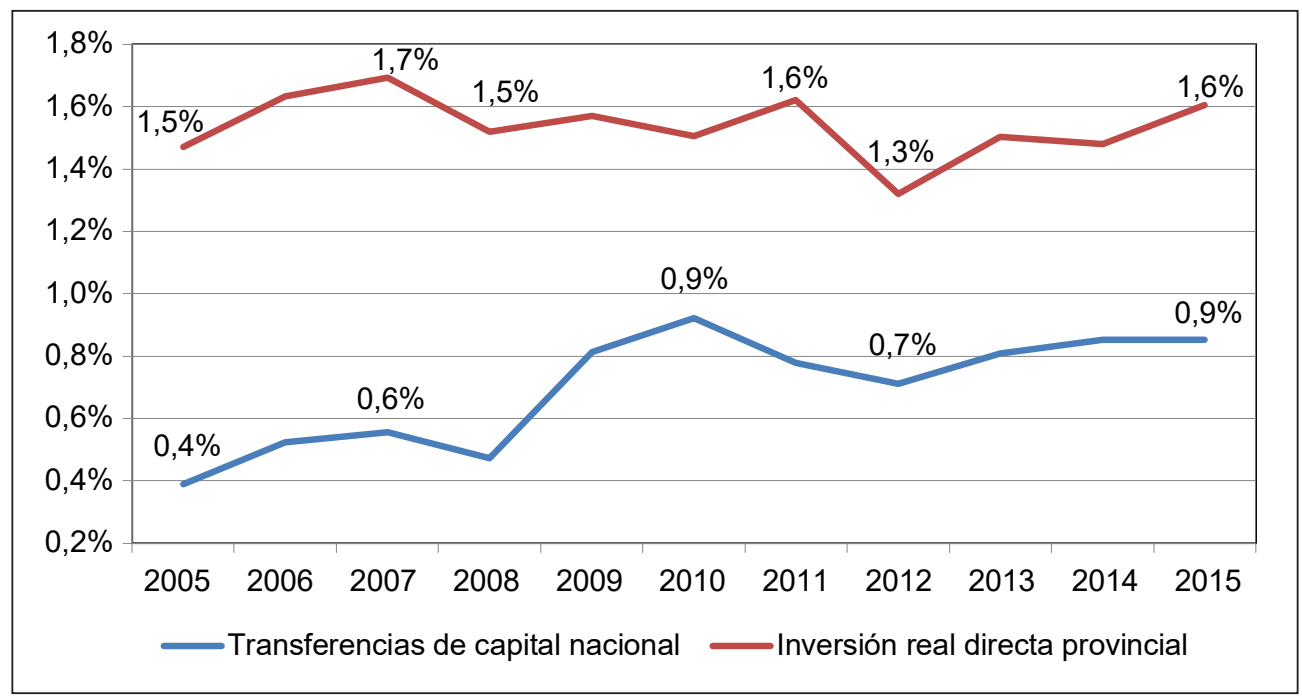

Fuente: elaboración propia con datos de la DNCFP.

Así, el nivel de las trasferencias de capital — promedio durante el periodo 2003-2014_- pese a su carácter redistributivo hacia las regiones con menor participación en el PBG, manifestó disparidades importantes. Las regiones NOA y NEA fueron las más beneficiadas, aunque las diferencias entre ellas son notables (gráfico 9). A su vez, las distancias también se observaron entre la región NOA y Cuyo, si bien mostraron similar participación en el PBG. Por último, fue muy reducida la participación de la región Centro, que no llegó a recibir el 1 \% de estas transferencias en relación con su producto.

Estas diferencias se hicieron más evidentes cuando se analizaron las transferencias que recibió cada provincia (véase la tabla 1), de acuerdo con su agrupación regional. En este sentido, dentro de la región NEA - que tuvo la mayor participación en las transferencias de capital — fueron notables las diferencias de la Provincia de Formosa (32,02 \%) respecto a las demás: prácticamente duplicó lo recibido por Chaco (18,20\%). Estas disparidades han sido más contundentes en relación con Misiones (9,22 \%) y Corrientes (4,15\%).

una gran cantidad de leyes con asignaciones específicas que detraen recursos de la masa coparticipable y otorgan mayor discrecionalidad en su disposición a Nación, junto con una ley de coparticipación que se viene prorrogando sucesivamente desde el año 1988, con criterios de distribución primarios y secundarios desactualizados. Para un mejor tratamiento de estas cuestiones, véanse Cao (2008), Rezzoagli (2011) y Capello et. al. (2016). 
La intervención fiscal del Estado en el fortalecimiento de la producción industrial en las regiones: el caso argentino ...

Gráfico 9. Transferencia de capital nacional por regiones, promedio 2003-2014 (porcentaje del PBG)

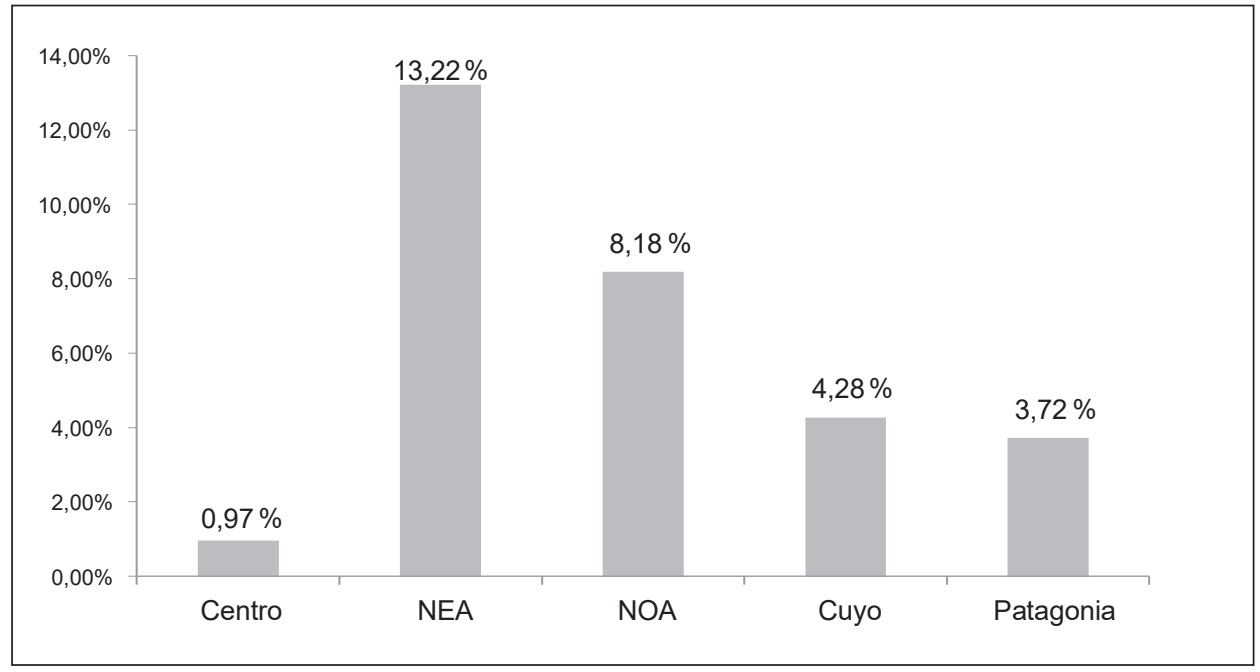

Fuente: elaboración propia con datos de ASAP y DNCFP.

Tabla 1. Transferencias de capital nacional por provincia* (porcentaje del PBG)

\begin{tabular}{|l|c|l|c|}
\hline \multicolumn{1}{|c|}{ Provincia } & Transferencia & \multicolumn{1}{c|}{ Provincia } & Transferencia \\
\hline Formosa & $32,02 \%$ & Río Negro & $3,93 \%$ \\
\hline La Rioja & $21,78 \%$ & Salta & $4,66 \%$ \\
\hline Chaco & $18,20 \%$ & Tierra del Fuego & $4,52 \%$ \\
\hline Santiago del Estero & $16,82 \%$ & Catamarca & $3,63 \%$ \\
\hline Jujuy & $11,66 \%$ & Chubut & $2,11 \%$ \\
\hline San Juan & $9,56 \%$ & San Luis & $1,96 \%$ \\
\hline Misiones & $9,22 \%$ & Mendoza & $1,90 \%$ \\
\hline Tucumán & $8,94 \%$ & Neuquén & $1,52 \%$ \\
\hline Santa Cruz & $7,57 \%$ & Córdoba & $1,31 \%$ \\
\hline Entre Ríos & $6,05 \%$ & Santa Fe & $1,18 \%$ \\
\hline La Pampa & $6,04 \%$ & Buenos Aires & $1,06 \%$ \\
\hline Corrientes & $4,15 \%$ & CABA & $0,15 \%$ \\
\hline
\end{tabular}

* Ordenadas de mayor a menor.

Fuente: elaboración propia con datos de ASAP y DNCFP. 
La disparidad también se observó sobre la región NOA, como la segunda región que recibió más transferencias de capital nacionales. En este caso, las provincias más favorecidas fueron Santiago del Estero (16,82 \%) y Jujuy (11,66 \%), las que duplicaron —al menos — la participación recibida por Salta (4,66 \%) y Catamarca (3,63 \%).

Pese a tener un porcentaje de participación similar en las transferencias de capital nacional recibidas, las disparidades se observaron tanto en la región Cuyo como en la de Patagonia. Por un lado, fue llamativa la diferencia que la provincia de La Rioja (21,78 \%) tuvo no solo respecto a las demás provincias de la región Cuyo, sino también respecto a las de la región Patagonia: La Rioja fue la segunda provincia que más transferencias de capital —en porcentajes del PBG — recibió luego de Formosa. Por otro lado, respecto a la región Patagonia, fueron importantes las diferencias que la provincia de Santa Cruz ha tenido sobre las demás. En particular, la disparidad es llamativa respecto a Río Negro y Chubut, debido a que estas dos provincias tienen mayor densidad poblacional ${ }^{7} \mathrm{y}$, a su vez, cuentan con superficies territoriales similares. ${ }^{8}$

Las mismas diferencias se plantearon respecto a la región Centro, como la menos favorecida en la recepción de transferencias. En este caso, las mínimas participaciones recibidas por la Ciudad Autónoma de Buenos (0,15\%), la Provincia de Buenos Aires (1,06 \%), Santa Fe (1,18 \%) y Córdoba (1,31 \%) contrastaron con los porcentajes de Entre Ríos (6,05 \%) y La Pampa (6,04 \%).

Al remarcarse estas cuestiones no se pretende soslayar, como se mencionó, la importancia redistributiva de estas transferencias, pero sí destacar los criterios utilizados para ejecutar las mismas, y más aún cuando la mayor parte de estas transferencias tiene un alto grado de discrecionalidad en su disposición. Ello es así debido a que las mismas son financiadas con recursos propios del tesoro nacional, no tienen carácter automático y, en general, su uso se encuentra condicionado a determinados destinos que son considerados como prioritarios por Nación (DNCFP, 2015). Estos aspectos de las transferencias habilitan su manejo arbitrario, provocando que, como lo sostienen Capello et al. (2016), sean más sensibles a cambios de política y vaivenes de las finanzas del Estado nacional.

Por último, y como complemento de lo anterior, se agregó el hecho de que la inversión pública del Estado nacional — con ejecución directa sobre las Provin-

7 Según datos de la Dirección Nacional de Relaciones con las Provincias, dependiente de la Secretaria de Hacienda del Ministerio de Hacienda y Finanzas Públicas de la Nación, la densidad poblacional de Río Negro es de 3,49 habitantes por $\mathrm{km}^{2}$ (ocupa el lugar 21 en la comparación interprovincial) y la de Chubut, de 2,57 (lugar 22); mientras que en Santa Cruz es de 1,35 (lugar 24).

8 De acuerdo con datos del Indec, la superficie territorial de Chubut es de $224.686 \mathrm{~km}^{2}$; la de Río Negro, de $203.013 \mathrm{~km}^{2}$; y la de Santa Cruz, de $243.943 \mathrm{~km}^{2}$. 
cias - no compensó la disparidad de criterios que presentaron las transferencias de capital; por el contrario, en algunos casos tendió a reforzarla. De acuerdo con el gráfico 10, se pudo observar que nuevamente la región NEA recibió mayor cantidad de inversiones del Estado nacional —en aproximadamente un $12 \%$ de su PBG-. Por su parte, la región Cuyo (6 \%) y más aún, la región Centro $(0,45 \%$ ) recibieron menor inversión.

Gráfico 10. Inversión pública nacional en las regiones, 2003-2012 (promedio porcentual del PBG)

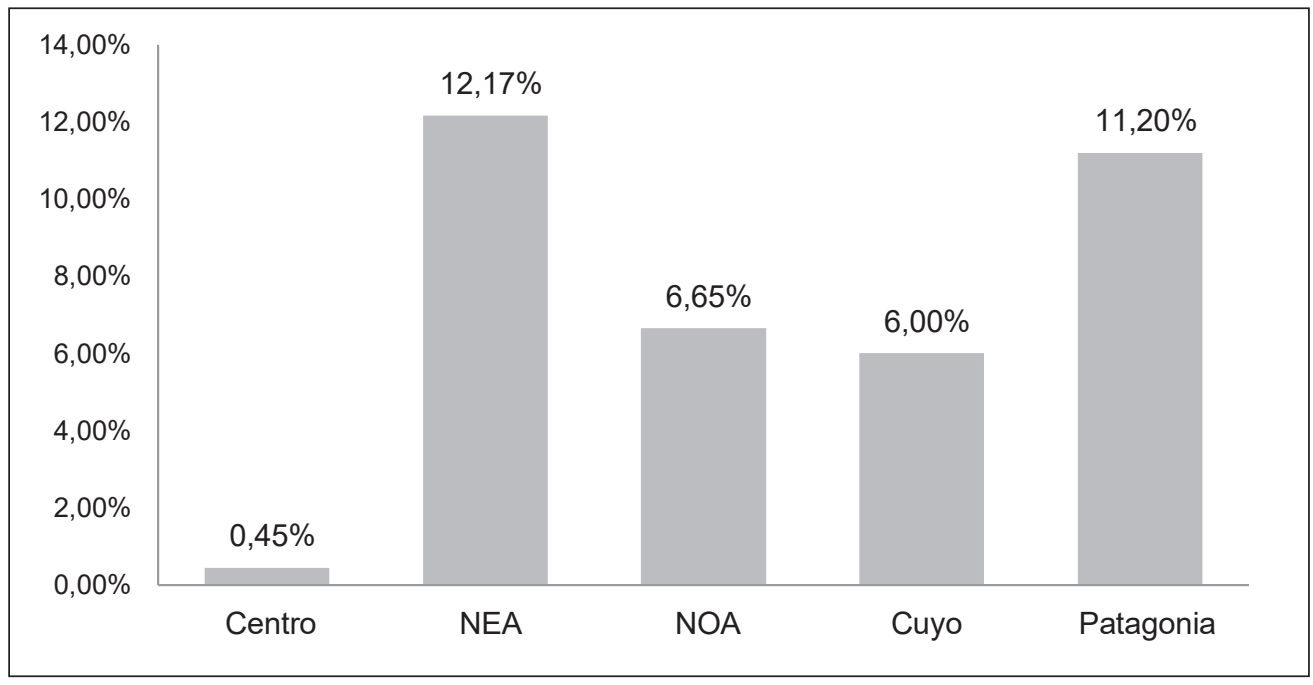

Fuente: elaboración propia con datos del Ministerio del Interior, Obra Pública y Vivienda de la Nación.

La distinción se presentó respecto a la Patagonia, que fue la segunda región más beneficiada en términos del producto. Sin embargo, esta última junto a la región NEA duplican al resto en cuanto a recepción de inversiones directas del Estado nacional. Estas diferencias son mayores respecto a la región Centro, nuevamente la más perjudicada. Este aspecto da lugar a situaciones de escasa o inadecuada infraestructura económica y social dado que esta región no solo participa con el mayor porcentaje de PBG, sino que es la más poblada.

\subsection{Subsidios económicos}

Los escasos niveles de inversión pública con criterios dispares en distribución regional se acompañaron de un sistema de subsidios económicos que comenzó a tener lugar luego de la devaluación del año 2002.9 Como lo señalaron Lombardi

9 "La Ley de Emergencia Económica n. 25.561, sancionada el 6 de enero de 2002, dispuso pesificar las tarifas de los servicios públicos de gas y electricidad de su valor original en pesos convertibles a dólares estadounidenses a pesos a un tipo de cambio de \$ 1 por cada dólar; se revocaron todas las 
et al. (2014), estos subsidios apuntaron a congelar los precios de los servicios públicos, para evitar la generación de pérdidas en las empresas proveedoras luego del gran incremento de costos. Así, debido a que permitían mantener tarifas bajas con un tipo de cambio elevado, los subsidios — en particular, del Estado nacional — se fueron convirtiendo en una herramienta fundamental dentro de la política económica (Castro et al., 2015).

Esta cuestión explicó el preponderante aumento del gasto público en transferencias corrientes al sector privado — fundamentalmente, desde 2007 en adelante-, consideradas como subsidios por las normas internacionales vigentes provenientes de las Estadísticas Fiscales del Fondo Monetario Internacional (FMI, 2012). El incremento de estas transferencias en un 4 \% del PIB entre los años 2003 y 2015, llegó a duplicar los niveles de IRD (véase el gráfico 11, panel izquierdo) y fue representado de forma preponderante por subsidios económicos del Estado nacional en los servicios de energía y transporte (gráfico 11, panel derecho).

La significancia alcanzada por estos subsidios nacionales es notable, dado que solo el $2 \%$ restante del producto es representado por las provincias y demás entes del sector público argentino para el año 2014, y en general, para todo el periodo 2006-2015.

Esto se tradujo en un aumento del gasto público consolidado en la finalidad servicios económicos entre los años 2004 y 2015: pasó del 9 al 14 \% del gasto total (véase el gráfico 12, paneles izquierdo y derecho). Este incremento porcentual, en detrimento de las demás finalidades de gasto — gasto social, funcionamiento del Estado y servicios de la deuda pública -, estuvo directamente vinculado al aumento en la participación del gasto a las funciones de energía y combustible y transporte, dentro de la finalidad servicios económicos (ver gráfico 12, panel inferior).

El gasto en general tuvo una escasa incidencia no solo en la función producción primaria sino —y fundamentalmente — en la función industria: en esta se contemplan las cantidades de financiamiento destinadas a programas cuyas metas son la regulación, control y fomento de la actividad industrial realizada por el sector privado, así como la realización de tareas industriales por el sector público, incluidas las que gestionan y administran subsidios diversos a empresas del sector. En este sentido, se vio que no obstante los leves aumentos de gasto hacia la función industria en porcentajes del PIB desde el año 2010, los mismos apenas alcanzaron el 0,17 \% del producto en 2015.

disposiciones relativas a ajustes de precio y los mecanismos de indexación previstos en los contratos vigentes" (Instituto Argentino de Energía "General Mosconi" y Asociación Argentina de Presupuesto y Administración Financiera Pública, 2015, p. 6). 
La intervención fiscal del Estado en el fortalecimiento de la producción industrial en las regiones: el caso argentino ...

Gráfico 11. Arriba: transferencias corrientes al sector privado y la inversión real directa del Spanf (porcentaje del PIB); abajo: evolución de los subsidios económicos nacionales (porcentaje del PIB)
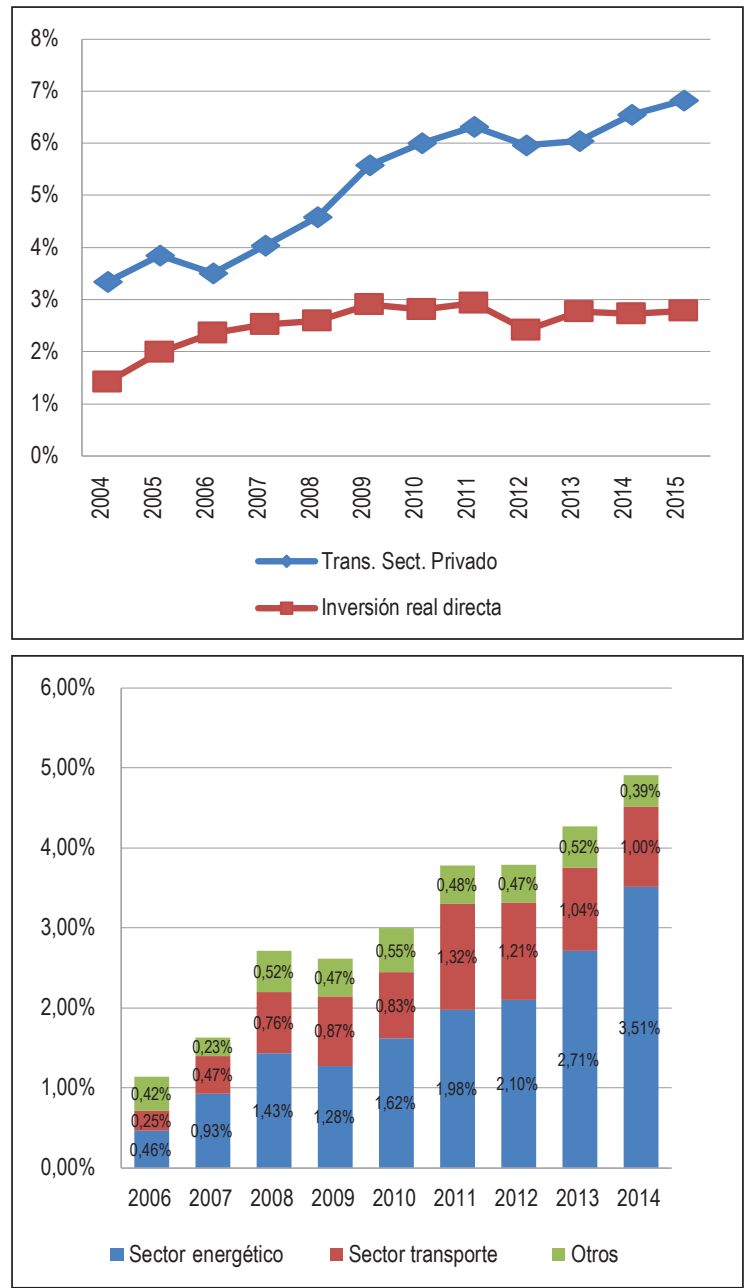

Fuente: elaboración propia con datos de la ONP (arriba) y del Instituto Argentino de Análisis Fiscal (laraf) y ASAP (abajo). 
Gráfico 12. Distribución porcentual del gasto público consolidado* por finalidades, años 2004 (izquierda) y 2015 (derecha); panel inferior: gasto público consolidado por funciones en la finalidad servicios económicos, en porcentaje del PIB
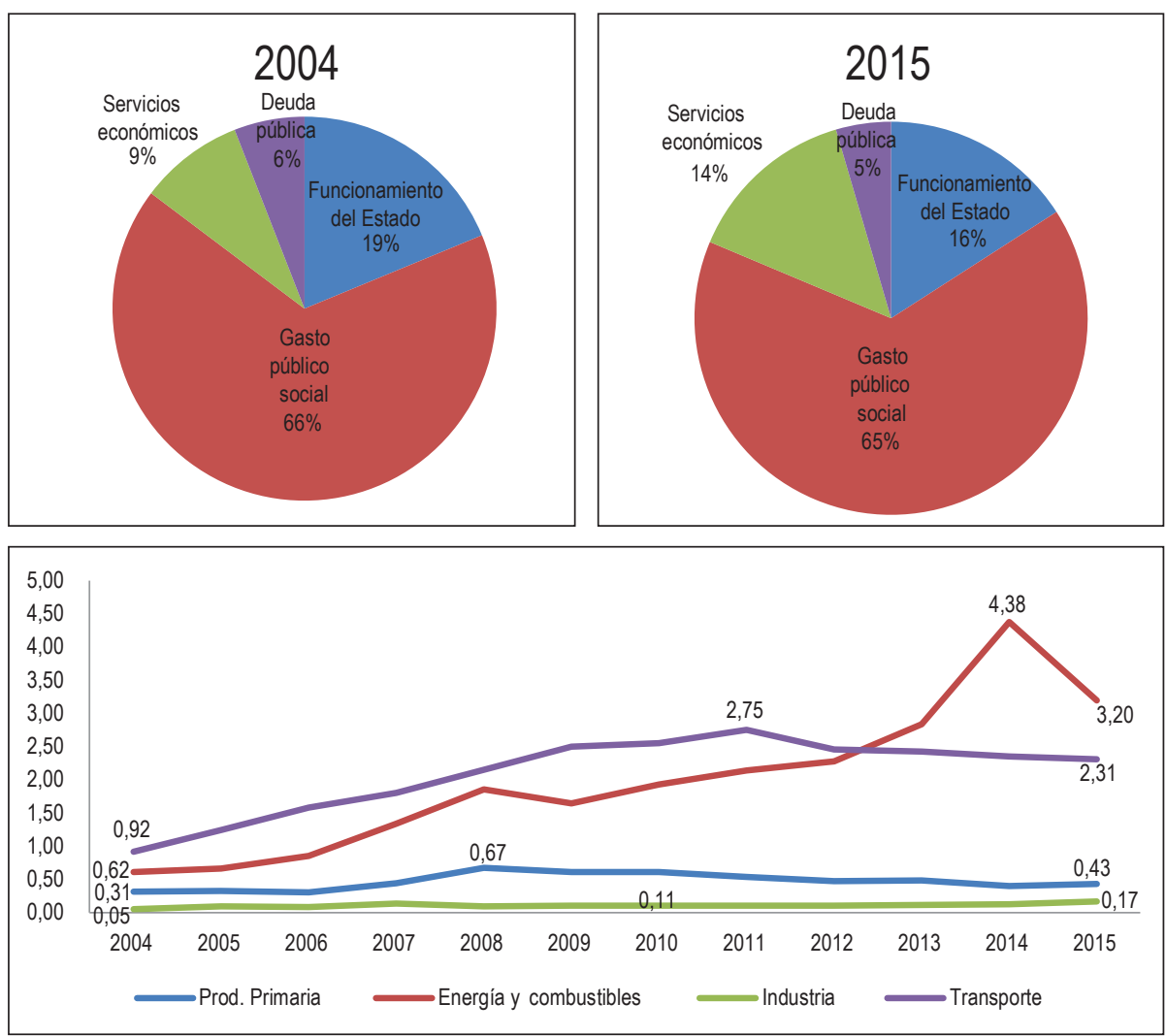

* Se incluye el gasto público de los tres niveles de gobierno (nacional, provincial y municipal)

Fuente: elaboración propia con datos del Ministerio de Hacienda de la Nación

En función de los datos referenciados, se plantearon dos consecuencias directas del incremento de los subsidios económicos. Por un lado, sin desconocer su importante impacto redistributivo sobre el consumo, su aumento no significó una mejora en la oferta productiva de estos servicios. No obstante la concreción de algunos proyectos específicos relevantes, como el Plan Federal de Transporte Eléctrico, el reinicio de las obras en la central Atucha II, la finalización de la represa hidroeléctrica de Yacyretá, y la reestatización de los Yacimientos Petrolíferos Fiscales (YPF), los avances para diversificar la producción energética fueron limitados; y ello tuvo su manifestación en el balance energético nacional desde 2011, con el importante incremento de las importaciones en detrimento de las exportaciones (tabla 2). 
La intervención fiscal del Estado en el fortalecimiento de la producción industrial en las regiones: el caso argentino ...

Tabla 2. Balance energético nacional (en miles de TEP*)

\begin{tabular}{|c|c|c|}
\hline Año & Importaciones & Exportaciones \\
\hline 2003 & 4.153 & 27.576 \\
\hline 2004 & 7.237 & 24.534 \\
\hline 2005 & 6.843 & 21.971 \\
\hline 2006 & 7.058 & 19.239 \\
\hline 2007 & 8.533 & 13.975 \\
\hline 2008 & 8.105 & 12.144 \\
\hline 2009 & 8.429 & 13.057 \\
\hline 2010 & 10.930 & 12.515 \\
\hline 2011 & 15.563 & 10.265 \\
\hline 2012 & 15.619 & 9.920 \\
\hline 2013 & 18.920 & 8.228 \\
\hline 2014 & 18.739 & 8.262 \\
\hline 2015 & 18.355 & 6.477 \\
\hline
\end{tabular}

* Tonelada equivalente de petróleo.

Fuente: elaboración propia con datos del Ministerio de Energía y Minería.

El déficit energético planteado en 2011, y su agravamiento en los años siguientes, fue uno de los principales factores que contribuyeron a la agudización de la restricción externa durante esos años ${ }^{10}$. Junto a la reducción de la demanda externa de algunos productos de exportación como consecuencia de la crisis internacional del año 2008, y sumado a ello, la caída en los precios internacionales desde 2011 en adelante, el déficit energético fue otro de los aspectos preponderantes que desencadenó la desaceleración macroeconómica y la insostenibilidad del exponencial crecimiento alcanzado durante los primeros años del periodo."

Por otro lado, el gasto del Estado nacional per cápita en la finalidad servicios económicos - en su mayor parte destinado a los subsidios — fue profundamente focalizado, con importantes desigualdades entre regiones y provincias. Más de un 70 \% del gasto per cápita total fue representado solo por dos jurisdicciones: la Ciudad Autónoma de Buenos Aires (CABA), lugar donde se produce la histórica concentración económico-demográfica del país; y la otra, la despoblada provincia de

10 Véanse Amico (2013b) y Amico, Fiorito y Zelada (2012).

11 Otro de los factores que influyó directamente en la restricción, fue el proceso de remisión de utilidades y dividendos por parte del capital extranjero hacia el exterior, así como la fuga de capitales que comenzó a agudizarse con los controles cambiarios establecidos en 2011. Al respecto, consúltense Gaggero et al. (2014) y Grondona (2014). 
Santa Cruz (véase la tabla 3). Aproximadamente un 10 \% se distribuyó en las Provincias de Formosa, Tierra del Fuego y Río Negro, mientras que el 20 \% restante fue para el resto de las jurisdicciones.

Tabla 3. Ubicación Geográfica del gasto de la administración pública nacional en servicios económicos per cápita, promedio 2005-2014 (en pesos corrientes y porcentaje del gasto per cápita total)

\begin{tabular}{|l|c|c|}
\hline \multicolumn{1}{|c|}{ Provincias } & $\begin{array}{c}\text { En pesos corrientes per } \\
\text { cápita }\end{array}$ & $\begin{array}{c}\text { \% del gasto per cápita } \\
\text { total }\end{array}$ \\
\hline CABA & $20.639,60$ & $51,15 \%$ \\
\hline Santa Cruz & $7.636,30$ & $18,93 \%$ \\
\hline Formosa & $1.776,40$ & $4,40 \%$ \\
\hline Tierra del Fuego & $1.177,30$ & $2,92 \%$ \\
\hline Río Negro & 973,60 & $2,41 \%$ \\
\hline Otras & $8.145,50$ & $20,19 \%$ \\
\hline
\end{tabular}

Fuente: elaboración propia con datos de la Subsecretaría de Coordinación Provincial.

Con lo anterior, el mayor incremento de los gastos en servicios económicos, pese a sus alcances redistributivos, no tuvo como destino prioritario el fortalecimiento de la capacidad productiva de la industria y evidenció, al igual que la inversión pública, limitaciones en la coordinación fiscal nacional y provincial. El primer aspecto se reflejó no solo en la escasa incidencia del gasto para ampliar la producción energética, sino también en los bajos niveles de financiamiento que recibió la mencionada función industrial. Ello fue un elemento común del gasto público que compartieron tanto Nación como las Provincias. Sobre esa base, el segundo aspecto se explicó por las importantes diferencias entre determinadas jurisdicciones provinciales respecto a las demás.

\subsection{Gastos tributarios nacionales}

Para concluir el tratamiento sobre la intervención fiscal y su incidencia sobre la capacidad productiva de la industria, resulta importante adentrarse en el tratamiento de los gastos tributarios. Estos representaron aproximadamente el 0,50 \% del producto en el promedio del periodo 2004-2015. ${ }^{2}$ Sin embargo, la participación que los

12 Para observar con mayor detalle de qué organismos proviene la información para realizar la estimación, y la metodología utilizada para la identificación de los casos de Gasto Tributario, véase https://www. economia.gob.ar/sip/dniaf/gastos_tributarios_2014-16.pdf 
La intervención fiscal del Estado en el fortalecimiento de la producción industrial en las regiones: el caso argentino ...

distintos regímenes promocionales han tenido sobre los mismos ha ido variando a lo largo del periodo. Debido a ello, el trabajo se centró en tres años (2004, 2010 y 2015) de gran significancia por las modificaciones que han tenido lugar.

En este sentido, un primer aspecto que se desprendió del análisis, fue la creciente participación que se ha destinado a la promoción económica de la provincia de Tierra del Fuego, Antártida e Islas del Atlántico Sur. ${ }^{13}$ En línea con Schorr y Porcelli (2014), el esquema de incentivos, pese a sus alteraciones en diversos momentos, gira en torno a la liberación de aranceles al comercio exterior y la eximición del pago de tributos nacionales (fundamentalmente, por su importancia, el IVA y el impuesto a las ganancias). Como pudo observarse, alcanzó más del 70\% del gasto tributario total para el año 2015 (ver gráfico 13, panel inferior). Su evolución ha sido notable, destacándose que para el año 2004 solo alcanzaba el 38\% del total (ver gráfico 13, panel izquierdo).

Ahora bien, a pesar de la relevancia económica de este régimen y su importancia estratégica en términos económicos y geopolíticos, esta promoción presenta ciertas limitaciones no solo porque la mayor parte se concentra en una sola provincia sino, y fundamentalmente, por el perfil productivo de la industrial fueguina ${ }^{14}$. En relación a este perfil, y siguiendo con los aportes de Schorr y Porcelli (2014), no obstante su impacto en la creación de puestos de trabajo y el despliegue de diversos efectos multiplicadores, que se asocian al desarrollo de nuevos rubros de actividad (comercial, logística, inmobiliaria, de reparación y mantenimiento, etc.), su preponderante vinculación al segmento de la electrónica del consumo hace que la incidencia de los incentivos para fortalecer la capacidad productiva de la industria sea limitada.

Por un lado, ello se debe al elevado coeficiente de importaciones en las funciones de producción de las firmas, como resultado — principalmente- de un set de incentivos que eximen el pago de aranceles para la importación de materias primas y maquinarias. En consecuencia, el régimen tiene una fuerte dependencia tecnológica externa y "desarrollos tecnológicos locales escasos, los que se focalizan mayormente en el diagrama de los flujos de producción y los lay out de fábrica, antes que en el diseño de productos" -véase, Schorr y Porcelli (2014, p. 7) —. Esta cuestión caracteriza al régimen fueguino con un perfil ensamblador de bienes que provienen del exterior, lo que genera una escasa integración de los procesos industriales con el resto del espacio nacional.

13 Los orígenes de esta promoción se encuentran en la Ley n. ${ }^{\circ} 19.640$ de 1972, la cual estableció un régimen fiscal y aduanero especial.

14 Escapa al objeto de este trabajo hacer un desarrollo más extenso sobre las características productivas del régimen fueguino. Para un tratamiento detenido sobre el mismo en el periodo reciente, véanse Schorr y Porcelli (2014), y González Passetti (2014). 
Gráfico 13. Gastos tributarios en regímenes de promoción económica'5 - años 2004 (panel izquierdo), 2010 (panel derecho) y 2015 (panel inferior), en \% del gasto tributario total
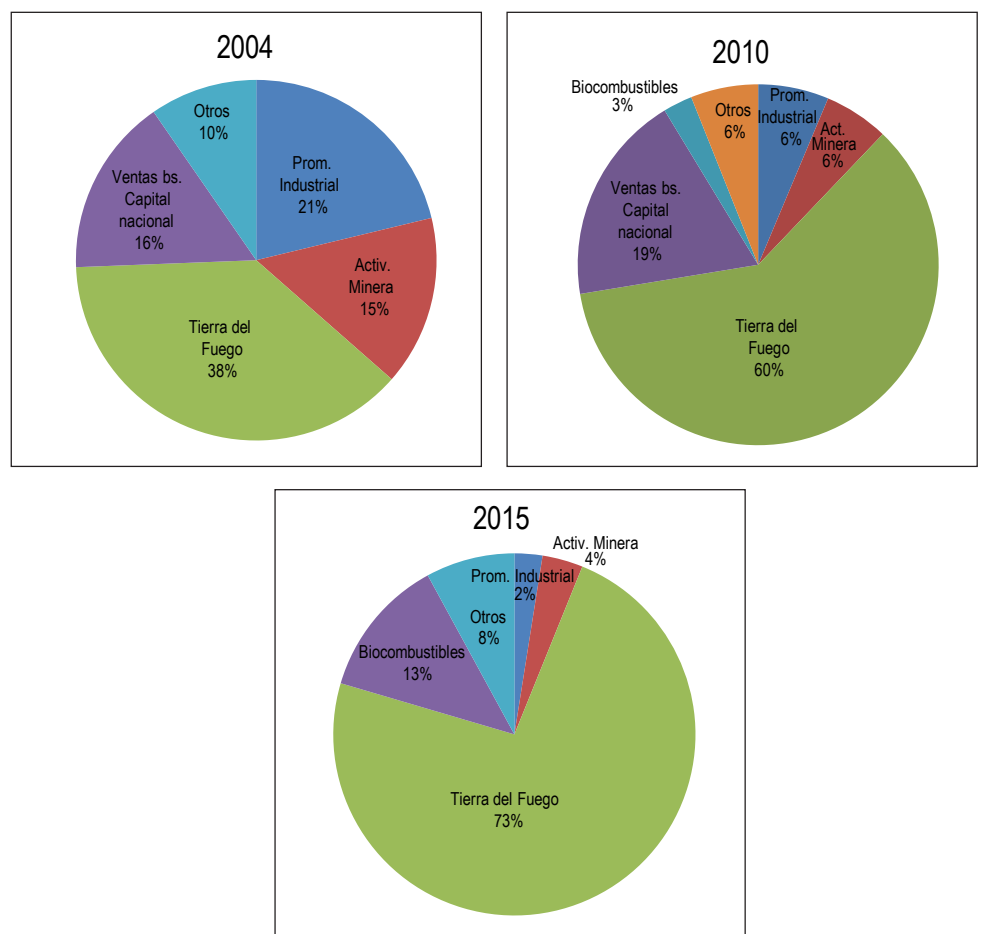

Fuente: elaboración propia con datos del Ministerio de Hacienda y Finanzas Públicas

Por un lado, ello se debe al elevado coeficiente de importaciones en las funciones de producción de las firmas, como resultado — principalmente - de un set de incentivos que eximen el pago de aranceles para la importación de materias primas y maquinarias. En consecuencia, el régimen tiene una fuerte dependencia tecnológica externa y "desarrollos tecnológicos locales escasos, los que se focalizan mayormente en el diagrama de los flujos de producción y los lay out de fábrica, antes que en el diseño de productos" - véase, Schorr y Porcelli $(2014$, p. 7) - . Esta cuestión caracteriza al régimen fueguino con un perfil ensamblador de bienes que provienen del exterior, lo que genera una escasa integración de los procesos industriales con el resto del espacio nacional.

15 Se comprende a los gastos tributarios totales originados en regímenes de promoción económica; además de la promoción económica en Tierra del Fuego por Ley n. 19.640 y normas complementarias, incluye promoción industrial y no industrial; y promoción de la actividad minera, de las pequeñas y medianas empresas, del fomento de la investigación y el desarrollo científico y tecnológico, de fomento de la educación técnica, de inversiones para bosques cultivados, de la industria del software, de apoyo al empresariado joven, de obras de infraestructura crítica, y de la producción y uso sustentable de biocombustibles. 
La intervención fiscal del Estado en el fortalecimiento de la producción industrial en las regiones: el caso argentino ...

Por otro lado, este perfil ensamblador del entramado productivo orienta su fabricación — preponderantemente - al mercado interno, y no a las exportaciones. Ello se desprende, básicamente, por el efecto que el régimen promocional tiene sobre la liberación del pago del IVA, como un impuesto que sólo grava las ventas realizadas en el nivel doméstico.

Por lo tanto, estos aspectos contribuyen no solo a un importante esfuerzo fiscal para el Estado — en función de los tributos que deja de percibir — sino también a uno de los problemas medulares para avanzar en la transformación de la estructura productiva y ampliar capacidades industriales regionales, que se relaciona con el desbalance comercial y su consecuente restricción externa —véase, González Passetti (2014) —.

En contraste con el régimen fueguino, los demás regímenes que tuvieron una participación relevante sobre el gasto tributario total, y que contribuyen directamente a un proceso sustitutivo o de mayor generación de exportaciones, como por ejemplo el régimen de promoción industria ${ }^{16} \mathrm{y}$ los reintegros a las ventas de bienes de capital de fabricación nacional, fueron perdiendo su importancia en el tiempo, en particular desde 2011. El primero de estos regímenes, que consiste en la subvención de impuestos internos a las actividades industriales que se radiquen en el territorio nacional, paso del $21 \%$ del gasto tributario total en 2004 (véase el gráfico 13, panel izquierdo) a solo el 6 \% en 2010 (panel derecho) y el 2 \% en 2015 (panel inferior).

Por su parte, es interesante lo ocurrido con los reintegros aplicados sobre la venta de bienes de capital de fabricación nacional, sus partes y accesorios. Esta promoción es aplicable, como así lo establece el Decreto n. 379/2001, a los establecimientos industriales radicados en el territorio nacional, con el objetivo de lograr una mayor competitividad de la industria local para que pueda participar en condiciones equitativas en la provisión de tales bienes, promoviendo así su fabricación nacional. Este reintegro, que cuenta con una relevancia fundamental para promover procesos de industrialización de bienes de capital, ha mantenido su participación sobre el gasto tributario total, pasando del $16 \%$ para el año 2004 al $19 \%$ para 2010 (véase el gráfico 13, paneles izquierdo y derecho). Sin embargo, luego de este año, y hasta el 2015 fue perdiendo completamente su participación (gráfico 13, panel inferior).

La nota distintiva fue marcada por la promoción al régimen para la producción y uso sustentable de los biocombustibles. ${ }^{17}$ Este régimen comenzó a tener una participación tardía en el periodo considerado, pero relevante: pasó de apenas el 3 \%

\footnotetext{
16 Creado sobre la base de los decretos 2054/1992, 804/1996, 1553/1998 y 2334/2000.

17 Leyes n. 26.093 de 2006 y 26.334 de 2008.
} 
del total de gasto para el año 2010 al 13 \% en 2015. Como sostiene Di Paola (2013), la promoción de este sector contribuye a la diversificación de la matriz energética, a crear nuevas posibilidades de empleo - principalmente en zonas extrapampeanas - y mejorar el balance de divisas. Sin embargo, y pese a señalarse su relevancia, su incipiente desarrollo tuvo, lógicamente, un impacto reducido para contrarrestar el desbalance comercial que se acentuaría a fines de 2010.

\subsection{Consideraciones sobre la capacidad productiva de las industrias regionales}

La intervención fiscal estatal que se observó en los apartados anteriores tuvo alcances restringidos durante el periodo 2003-2015 para acompañar, con el estímulo de políticas estructurales, el crecimiento económico exponencial alcanzado hasta fines de 2010. Por lo tanto, el acaecimiento de la crisis en 2011, dado el agravamiento de la restricción externa, repercutió directamente en la capacidad productiva de la industria en las regiones. Ello fue particularmente reflejado con al análisis del Iderp económico ${ }^{18}$, en el que se establecieron las consideraciones que se presentan a continuación.

En primer lugar, todas las regiones han ampliado la capacidad productiva de la industria durante el periodo 2004-2015. Inclusive, como lo muestra la tabla 4, el crecimiento de las regiones con menor participación en el PBG — NOA, Cuyo y NEAha superado el promedio nacional, y estas regiones han alcanzado niveles superiores o similares respecto a las regiones que cuentan con mayor participación en el mencionado producto - Centro y Patagonia - Esto puede vincularse, entre otras cosas, al fuerte impacto de la IRD en las regiones NEA y NOA, fundamentalmente a través de las transferencias de capital nacional que ambas recibieron (véase el gráfico 9), así como a la inversión pública que el Estado nacional ejecutó de forma preponderante en la región NEA (gráfico 10).

18 El Iderp económico resume nueve indicadores referidos a variables productivas y de infraestructura, relacionados a: empleo privado formal; tasa de actividad; consumo de energía eléctrica en actividades productivas; exportaciones de manufacturas de origen industrial; venta de gasoil y cantidad de gasoil comercializado a empresas; gas entregado a industrias; consumo de cemento; préstamos en entidades bancarias; y densidad de caminos pavimentados. Dado que cada indicador tiene su propia unidad de medida y escala particular, los nueve indicadores parciales fueron normalizados por la Subsecretaría a partir de los datos anuales de las provincias en el periodo 2004-2015. Para analizar en detalle la metodología de normalización y de construcción de los índices sintéticos, véase Subsecretaría de Coordinación Provincial (2016). 
La intervención fiscal del Estado en el fortalecimiento de la producción industrial en las regiones: el caso argentino ...

Tabla 4. Iderp económico, brecha de desarrollo

\begin{tabular}{|l|c|c|c|}
\hline \multicolumn{1}{|c|}{ Regiones } & 2004 & 2015 & $\begin{array}{c}\text { Crecimiento } \\
\text { porcentual anual } \\
2004-2015\end{array}$ \\
\hline Patagonia & 40,8 & 47,2 & 1,3 \\
\hline Centro & 35 & 42,9 & 1,9 \\
\hline Total país & 29,1 & 34,5 & 1,6 \\
\hline Cuyo & 27,7 & 34,4 & 2 \\
\hline NOA & 16,6 & 23,3 & 3,1 \\
\hline NEA & 13,6 & 16,8 & 1,9 \\
\hline
\end{tabular}

Fuente: Subsecretaría de Coordinación Provincial (2016).

Sin desconocer la relevancia de estos avances, sus alcances fueron limitados debido a que, cuando se analiza el porcentaje de variación anual del IDERP económico, se observa que los mayores porcentajes obtenidos durante el periodo 2004-2010 -inclusive luego de la crisis de 2008-, comenzaron a tener una reducción notable del año 2011 en adelante (véase el gráfico 14). Esta afectó a todas las regiones y coincidió con las limitaciones macroeconómicas originadas por los referidos problemas de restricción externa.

Lo anterior provocó que el crecimiento alcanzado por las regiones más rezagadas tuviera un impacto limitado para reducir brechas de desarrollo. Esto se desprendió del análisis sobre los cocientes entre el valor más alto y el más bajo en términos del IDERP-Económico ${ }^{19}$ existentes entre la región más desarrollada y la menos desarrollada, en cada uno de los años. Estas brechas se redujeron en apenas un $6,3 \%$ entre 2004 y 2015: pasaron de 3 a 2,81 (tabla 5).

19 Corresponde agregar la siguiente aclaración: "[...] el IDERP permite observar si una región está más o menos desarrollada que otra en función de los indicadores con que se mide; sin embargo no es posible cuantificar la magnitud de las diferencias en el desarrollo. Esto significa que si el valor del IDERP de una región es el doble de otra, no necesariamente ello implica que la primera tenga un nivel de desarrollo que duplica al de la segunda" (Subsecretaría de Coordinación Provincial, 2016, p. 8). 
Alcides Bazza - Víctor Ramiro Fernández

Gráfico 14. Iderp económico por región, 2004-2015 (variación porcentual anual)
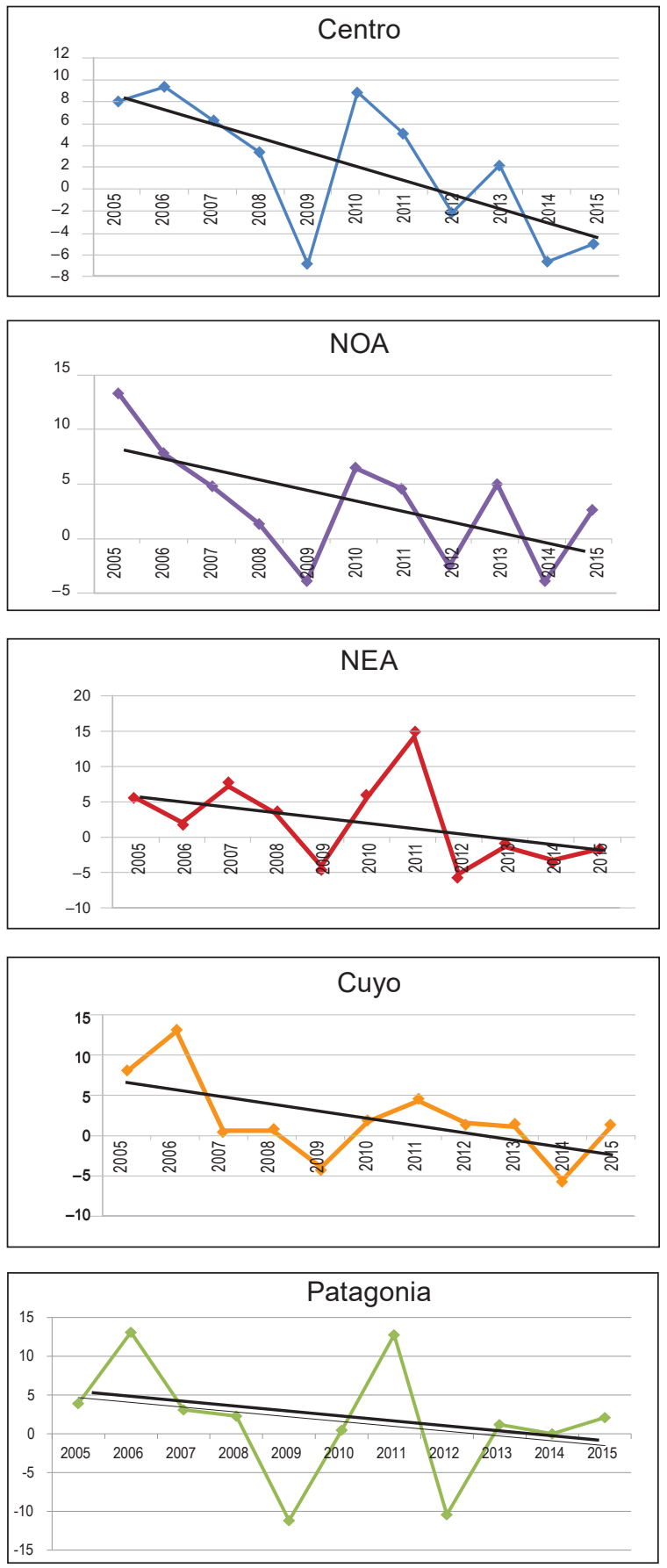

Fuente: elaboración propia con datos de la Subsecretaría de Coordinación Provincial (2016). 
Tabla 5. Iderp económico, brecha de desarrollo

\begin{tabular}{|l|c|c|}
\cline { 2 - 3 } \multicolumn{1}{c|}{} & \multicolumn{2}{c|}{ IDERP Económico por región } \\
\cline { 2 - 3 } \multicolumn{1}{c|}{} & 2004 & 2015 \\
\hline Centro & 35 & 42,9 \\
\hline NOA & 16,6 & 23,3 \\
\hline NEA & 13,6 & 16,8 \\
\hline Cuyo & 27,7 & 34,4 \\
\hline Patagonia & 40,8 & 47,2 \\
\hline Brecha de desarrollo & 3 & 2,81 \\
\hline
\end{tabular}

Fuente: elaboración propia con datos de la Subsecretaría de Coordinación Provincial (2016).

\section{CONCLUSIONES}

El presente trabajo analizó la intervención fiscal del Estado (nacional y provincial) en el fortalecimiento de la capacidad productiva de la industria en las regionales, durante la experiencia argentina reciente (2003-2015). Se destacó que la fiscalidad, en tanto uno de los elementos históricos de conformación del Estado, es clave no solo para estimular la demanda efectiva y el crecimiento económico, sino para promover transformaciones estructurales de base en la producción industrial. Este último aspecto fue de especial atención en este trabajo para considerar los alcances de la reacción neodesarrollista poscrisis del 2001, que colocó nuevamente el foco de atención en la reintervención del Estado para llevar adelante un fortalecimiento industrial nacional y revertir así las desigualdades productivas regionales.

En función de lo anterior, se consideraron la evolución de la inversión pública, los subsidios económicos (nacional y provincial) y los gastos tributarios nacionales en su incidencia cuantitativa sobre la capacidad productiva de la industria de cada región. A través de este análisis se observaron ciertas limitaciones para promover políticas estructurales que otorguen sostenibilidad al exponencial crecimiento económico alcanzado durante 2003-2010; se explicitan en la tabla 6.

Las limitaciones en la intervención fiscal del Estado (nacional y provincial) para incidir en el fortalecimiento de la capacidad productiva de la industria contribuyen, en no menor medida, a explicar la insostenibilidad del crecimiento económico exponencial alcanzado durante el periodo 2003-2010. Así, considerando el IDERP económico, la restricción externa agudizada en 2011 marcó un retroceso en los avances sobre las mencionadas capacidades en todas las regiones, y ello redujo los alcances para reducir brechas de desarrollo interregional. 
Tabla 6. Principales rasgos de la intervención fiscal nacional y provincial.

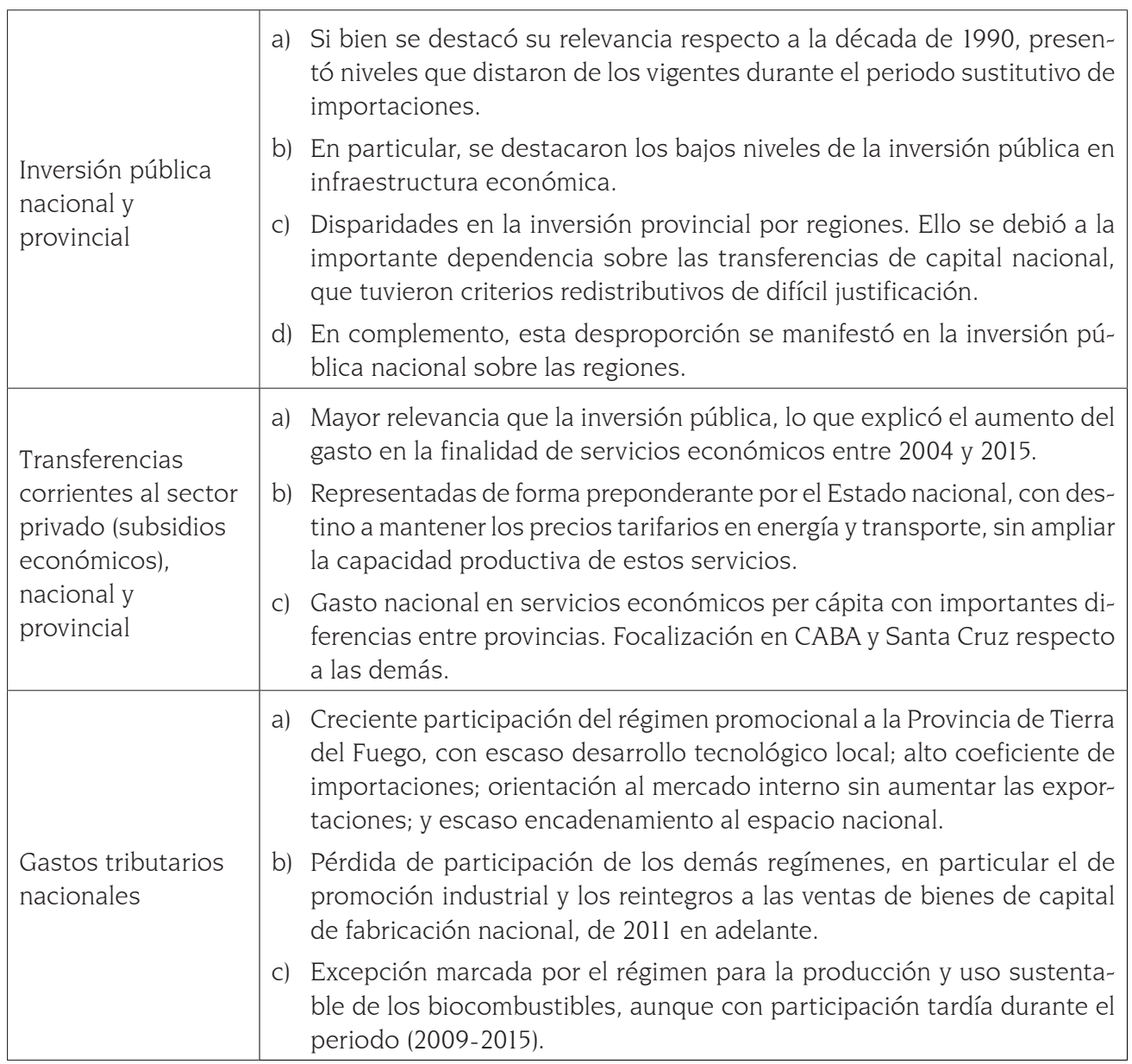

Fuente: elaboración propia.

Estas fueron las principales conclusiones de este trabajo, directamente vinculadas - y limitadas - a las variables de análisis consideradas. Sin duda, como se remarcó, el abordaje de la intervención del Estado en la problemática de las desigualdades productivas regionales demanda la consideración de múltiples aspectos. Las políticas monetarias, arancelarias, financieras, al igual que el abordaje de las estructuras burocráticas del Estado y sus capacidades para elaborar y planificar políticas, entre otras, son de importancia fundamental para lograr conclusiones más acabadas sobre este estudio.

Tampoco se pretendió desconocer la significativa importancia que ha tenido la política fiscal para estimular el crecimiento económico durante el periodo (véanse 
La intervención fiscal del Estado en el fortalecimiento de la producción industrial en las regiones: el caso argentino ...

Amico, 2013a, 2013b; Fiorito, 2015) y los notables avances en materia de gastos sociales e inclusión socioeconómica (véanse Agis et al., 2010 y Panigo, 2016). No obstante, el trabajo señaló desafíos pendientes en la intervención estatal de la reacción neodesarrollista para los fines de abonar a un replanteamiento que promueva la reflexión crítica, en la búsqueda de alternativas a futuro frente al retorno de las políticas conservadoras que se ha presentado desde finales de 2015.

\section{BIBLIOGRAFÍA}

Agis, Emmanuel; Cañete, Carlos y Panigo, Demián (2010). El impacto de la Asignación Universal por Hijo en Argentina. Observatorio de Trabajo Infantil y Adolescente. Ministerio de Trabajo, Empleo y Seguridad Social de la Nación, 54p.

Amico, Fabián (2013a). La política fiscal en el enfoque de Haavelmo y Kalecki. El caso argentino reciente. En: Centro de Economía y Finanzas para el Desarrollo de la Argentina (Cedif-AR), Documento de Trabajo n. ${ }^{\circ}$ 1, 61p.

Amico, Fabián (2013b). Crecimiento, distribución y restricción externa en Argentina. En: Circus, Revista Argentina de Economía, n. 5, p. 31-80.

Amico, Fabián; Fiorito, Alejandro y Zelada, Agustina (2012). Expansión económica y sector externo en la argentina de los años 2000: balance y desafíos hacia el futuro. En: Centro de Economía y Finanzas para el Desarrollo de la Argentina (CEDIF-AR), Documento de Trabajo n. ${ }^{\circ}$ 45, Buenos Aires, 118p.

Amsdem, Alice (1989). Asia's Next Giant: South Korea and Late Industrialization. Oxford: Oxford University Press, 379p.

Bell, Stephanie (2000). Do Taxes and Bonds Finance Government Spending? En: Journal of Economic Issues, Vol. 34, n. 3 , p. 603-620

Braun, Oscar y Joy, Leonard (1981). Un modelo de estancamiento económico. Estudio de caso sobre la economía argentina. En: Desarrollo Económico, Vol. 20, n. 80, p. 585-604.

Brenner, Neil (2004). New State Spaces: Urban Governance and the Rescaling of Statehood. Nueva York: Oxford University Press, 372p.

Cao, Horacio y Rubins, Roxana (1996). La cuestión regional y la conformación del Estado-Nación en la Argentina. En: Instituto Nacional de la Administración Pública, 52p.

Cao, Horacio (2008). Ortodoxia y revisionismo en el abordaje de la coparticipación federal de impuestos. En: Revista Aportes para el Estado y la Administración Gubernamental, Vol. 14, n. 26, p. $121-145$.

Capello, Marcelo y Diarte, Gustavo (2013). La inversión pública en las Provincias Argentinas. En: Monitor Fiscal, Fundación Mediterránea. Año 8, n.․ 22, abril.

Capello, Marcelo; Grión, Néstor y Toselli, Vanessa (2016). Diez puntos claves para la discusión fiscal entre Nación y Provincias. En: Monitor Fiscal, Fundación Mediterránea, n. 2 27.

Castells, Manuel (1989). Nuevas tecnologías y desarrollo regional. Economía y sociedad. En: Estudios regionales de la Comunidad de Madrid, n. ${ }^{\circ}$ 2, p. 11-22. 
Castells, María; Ferreira, Esteban; Inchauspe, Eugenia y Schorr, Martín (2014). La industria de bienes de capital en la posconvertibilidad: desempeño comercial externo y (des)aprovechamiento de la masa crítica existente. En: Realidad Económica, n. ํ2 283, p. 127-158.

Castro, Lucio; Szenkman, Paula y Lotitto, Estefanía (2015) ¿Cómo puede cerrar el próximo gobierno la brecha de infraestructura? En: Centro de Implementación de Políticas Públicas para la Equidad y el Crecimiento (Cippec), Análisis 148, marzo, 19p.

Cesaratto, Sergio; Serrano, Franklin y Stirati, Antonella (2003). Technical Change, Effective Demand and Employment. En: Review of Political Economy, Vol. 15, n.․ 1, p. 33-52.

Diamand, Marcelo (1973). Doctrinas económicas, desarrollo e independencia. Buenos Aires: Paidós, 464p.

Di Paola, María (2013). La producción de biocombustibles en Argentina. Informe Ambiental Anual de la Fundación Ambiente y Recursos Naturales, n. 13, p. 185-205.

DNCFP -Dirección Nacional de Coordinación Fiscal con las Provincias- (2015). El impacto de las transferencias presupuestarias del gobierno nacional en las provincias argentinas. En: IV Jornadas Iberoamericanas de Financiación Local, Cepal, 22p.

Fernández, Víctor (1999). Descentralización estatal y decisionismo fiscal. Enfoque crítico y propuestas a partir de la experiencia argentina 1960-1990. Editado en la Universidad Nacional del Litoral (UNL), 67p.

Fernández, Víctor (2001). Estrategia(s) de desarrollo regional bajo el nuevo escenario global-local: revisión crítica sobre su(s) potencialidad(es) y límites. En: EURE, Vol. 27, n. ㅇ 82, p. 43-63.

Fernández Víctor (2010). Desarrollo regional bajo transformaciones transescalares ¿Por qué y cómo recuperar la escala nacional? En: Fernández, Víctor y Brandao, Carlos (ed). Escalas y políticas del desarrollo regional. Desafíos para América Latina. Buenos Aires: Miño y Dávila, 349p.

Fernández, Víctor (2017). La trilogía del erizo-zorro. Redes globales, trayectorias nacionales y dinámicas regionales desde la periferia. Madrid: Anthropos y UNL Ediciones, 400p.

Fernández, Víctor; Tealdo, Julio y Villalba, Marta (2005). Industria, estado y territorio en la Argentina de los 90: evaluando la desimplicación estatal selectiva y repensando los caminos del desarrollo. Santa Fe: Universidad Nacional del Litoral, 304p.

Fernández, Víctor; Amin, Ash y Vigil, José (2008). Repensando el desarrollo regional. Buenos Aires: Miño y Dávila, 558p.

Fernández, Víctor y García Puente, María (2012). Revisando el Estado: perspectivas y lineamientos para el desarrollo latinoamericano. En: Perfiles Latinoamericanos, Vol. 20, n. ${ }^{\circ}$ 40, julio-diciembre, p. 35-61.

Fernández, Víctor y García Puente, María (2013). Estado, producción y desarrollo. Las capacidades nodales en una perspectiva latinoamericana. En: Revista Estado y Políticas Públicas, n. ${ }^{\circ}$ 1, p. 19-46.

Ferrer, Aldo (2007). Desarrollo e Integración: Desafíos y Oportunidades del Mercosur. Parte I y II. En: Revista Vértice. Caracas, n. ${ }^{\circ}$ 2, p. 7-9. 
La intervención fiscal del Estado en el fortalecimiento de la producción industrial en las regiones: el caso argentino ...

FMI -Fondo Monetario Internacional- (2012). Manual de estadísticas de finanzas públicas. Washington, D.C, 528p.

Gaggero, Alejandro; Schorr, Martín, y Wainer, Andrés (2014). Restricción eterna: el poder económico durante el kirchnerismo. Buenos Aires: Futuro Anterior, 176p.

Garegnani, Pierangelo (1977). Notas sobre consumo, inversión y demanda efectiva. En: El Trimestre Económico, Vol. 44, n. ${ }^{\circ}$ 175, p. 569-607.

González Passetti, Aldana (2014). Tierra del Fuego. La industria electrónica en la posconvertibilidad. En: Realidad económica, n. 284.

Gorestein, Silvia (2015). Transformaciones territoriales contemporáneas. Desafíos del pensamiento latinoamericano. En: Revista Eure, Vol. 41, n. ${ }^{\circ}$ 122, p. 5-26.

Grondona, Verónica (2014). La manipulación de los precios de transferencia y la fuga de capitales en Argentina. En: Centro de Economía y Finanzas para el Desarrollo de la Argentina (Cedif-AR), Documento de Trabajo n. ${ }^{\circ} 58$.

Grugel, Jean y Riggirozzi, Pía (2012). Post-neoliberalism in Latin America: Rebuilding and Reclaiming the State after Crisis. En: Development and Change, Vol. 43, n. ${ }^{\circ} 1$, p. 1-21.

Hirschman, Albert (1961). La estrategia del desarrollo económico. México, D.F.: Fondo de Cultura Económica, $211 p$.

IAE -Instituto Argentino de Energía- General Mosconi y ASAP -Asociación Argentina de presupuesto y Administración Financiera Pública- (2015). Los subsidios energéticos en Argentina, 18p.

Jessop, Bob (2006). ¿Narrando el futuro de la economía nacional y el Estado Nacional? Puntos a considerar acerca del replanteo de la regulación y la re-invención de la gobernancia. En: Documentos y Aportes en Administración Pública y Gestión Estatal, Vol. 6, n.ํㄱ, p. 7-44.

Kalecki, Michal (2002). Political Aspects of Full Employment. En: Joan Robinson (Ed.), Critical Assessments of Leading Economists, Vol. 2, n. ${ }^{\circ} 1 \mathrm{M} 3,21 \mathrm{p}$.

Lerner, Abba (1943). Functional Finance and the Federal Debt. En: Social Research, Vol. 10, n. ${ }^{\circ}$ 1, p. 38-51.

Lombardi, Manuel; Mongan, Juan; Puig, Jorge; y Salim, León (2014). Una aproximación a la focalización de los subsidios a los servicios públicos en Argentina. Documento de Trabajo n. 9 de la Dirección Provincial de Estudios y Proyecciones Económicas de la Provincia de Buenos Aires, 23p.

Mann, Michael (1993). The Sources of Social Power (Vol. 2). Nueva York: Cambridge University, 578p.

Mann, Michael (2013). The Sources of Social Power: Globalisations (Vol. 4). Nueva York: Cambridge University Press, 496p.

Manzanal, Mabel (1999). La cuestión regional en la Argentina de fin de siglo. En: Realidad Económica, n.ำ166, p. 70-99.

Minsky, Hyman (1986). Stabilizing an Unstable Economy. New Haven, CT: Yale University Press, 436p. 
Nochteff, Hugo (2002). ¿Existe una política de Ciencia y tecnología en la Argentina? Un enfoque desde la economía política. En: Desarrollo económico, Vol. 41, n. 164, p. 555-598.

ONP -Oficina Nacional de Presupuesto- (2005). Ejecución del Sector Público Argentino. Cuenta Ahorro-Inversión-Financiamiento (1961-2004), 144p.

Oszlak, Oscar (1982). Reflexiones sobre la formación del estado y la construcción de la sociedad argentina. En: Desarrollo Económico, Vol. 21, n. 84, p. 531-548.

Panigo, Demián (2016). El crecimiento del bienestar en Argentina y sus efectos sobre niñas, niños y adolescentes. Avellaneda: Undav ediciones, 340p.

Pinto, Aníbal (1972). Notas sobre desarrollo, subdesarrollo y dependencias. En: El trimestre económico. Vol. 39, n.154, p. 243-264.

Prebisch, Raúl (1986). El desarrollo económico de la América Latina y algunos de sus principales problemas. En: Desarrollo económico, Vol. 26, n.ำ103, p. 479-502.

Rezzoagli, Luciano (2011). Asimetrías regionales y federalismo fiscal. Un enfoque jurídico-financiero institucional del caso argentino. En: Documentos y Aportes en Administración Pública y Gestión Estatal, Vol. 11, n. ${ }^{\circ}$ 17, p. 90-120.

Rofman, Alejandro y Romero, Luis (1997). Sistema socioeconómico y estructura regional en la Argentina. Buenos Aires: Amorrortu Editores, 336p.

Rofman, Alejando (1982). Desigualdades regionales y políticas de desarrollo regional en América Latina. En: Cuadernos del Centro de Estudios Urbanos y Regionales, n. ${ }^{\circ}$ 7, 163p.

Rofman, Alejandro (1997). Economías Regionales Extrapampeanas y Exclusión Social en el marco del Ajuste. En: Revista Eure, Vol. 23, n. ${ }^{\circ}$ 70, p. 19-37, Santiago de Chile.

Sader, Emir (2008). Refundar el Estado. Posneoliberalismo en América Latina. Consejo Latinoamericano de Ciencias Sociales-CLACSO, Buenos Aires, 90p.

Schorr, Martín y Porcelli, Lucas (2014). La industria electrónica de consumo en Tierra del Fuego. Régimen promocional, perfil de especialización y alternativas de desarrollo sectorial en la posconvertibilidad. En: Documentos de Investigación Social de la Universidad Nacional de San Martín, 30p.

Subsecretaría de Coordinación Provincial (2016). Indicador de desarrollo relativo provincial (IDERP). Resultados regionales. Evolución en el periodo 2004-2015. Ministerio de Hacienda y Finanzas Públicas de la Nación, 39p.

Tilly, Charles (1990). Coercion, Capital and European States, AD 990-1990. Cambridge: Basil Blackwell, 269p.

Veltz, Pierre (1996). Mundialización, ciudades y territorios: La economía del archipiélago. Barcelona: Ariel, 256p.

Wade, Robert (1999). El mercado dirigido. La teoría económica y la función del gobierno en la industrialización del este de Asia. México: Fondo de Cultura Económica, 560p.

Wray, Randall (2014). From the State Theory of Money to Modern Money Theory: An Alternative to Economic Orthodoxy. Levy Economics Institute of Bard College. Working Paper n. ${ }^{\circ}$ 792, 34p. 